\title{
How do climate and land use changes affect the water cycle? Modelling study including future drought events prediction using reliable drought indices
}

Article

Accepted Version

Afzal, M. and Ragab, R. (2020) How do climate and land use changes affect the water cycle? Modelling study including future drought events prediction using reliable drought indices. Irrigation and Drainage, 69 (4). pp. 806-825. ISSN 1531-0353 doi: https://doi.org/10.1002/ird.2467 Available at https://centaur.reading.ac.uk/91044/

It is advisable to refer to the publisher's version if you intend to cite from the work. See Guidance on citing.

Published version at: http://dx.doi.org/10.1002/ird.2467

To link to this article DOI: http://dx.doi.org/10.1002/ird.2467

Publisher: Wiley

All outputs in CentAUR are protected by Intellectual Property Rights law, including copyright law. Copyright and IPR is retained by the creators or other copyright holders. Terms and conditions for use of this material are defined in the End User Agreement. 


\section{CentAUR}

Central Archive at the University of Reading

Reading's research outputs online 
How the climate and land use changes affect the water cycle? Modelling study including the future drought events prediction using reliable drought indices

$$
\text { Afzal, M. }{ }^{1,2} \text { and R. Ragab }{ }^{1 *}
$$

\section{Abstract}

The two key factors that affect the water balance are climate and land-use changes. Although climate change models have been developed for global scale, the implementation of their predictions is commonly applied at catchment scale where the measurements are being carried out and the management takes place. To investigate the impacts of climate and land use changes on the hydrology, the Don Catchment in Yorkshire, UK, has been selected for this study. A physically based distributed catchment-scale (DiCaSM) model has been applied. The model simulates the surface runoff, groundwater recharge and drought indicators such as soil moisture deficit (SMD) and wetness index $(W I)$ of the root zone. The model was calibrated and validated against the observed river flow and the model efficiency was evaluated using the Nash-Sutcliffe Efficiency factor (NSE). During the calibration period (2011-2012), NSE was above $91 \%$ and during the validation period (1966-2012) was above $83 \%$. To study the impact of climate change on the streamflow and the groundwater recharge, UK Climate Projections (UKCP09) data was applied. Under current land use changes under different climate scenarios, the greatest decrease in streamflow and groundwater recharge is projected under medium and high emission scenarios. Considering the projected increase in winter precipitation, the increase did not contribute much into the streamflow and groundwater recharge due to prolonged drier summer and higher temperature during the summer and autumn seasons that resulted in an increase of evapotranspiration and soil moisture deficit (SMD). Climate change scenarios projected an increase in evapotranspiration, soil moisture deficit more importantly in the latter half of the current century and resulted in more extreme and severe drought events in comparison to the baseline period. To study the impact of land use changes on water balance,

\footnotetext{
${ }^{1}$ Centre for Ecology \& Hydrology (CEH), Wallingford, Oxfordshire, OX10 8BB, UK

${ }^{2}$ School of Earth and Ocean Sciences, Cardiff University, Main Building, Park Place, Cardiff, CF10 3AT

*Corresponding Author, R. Ragab, rag@ceh.ac.uk
} 
27 different possible scenarios were created. The increasing of woodland had the most significant impact

28 by reducing the stream flow by up to $17 \%$ and groundwater recharge by $22 \%$. Urbanization, could

29 lead to increase in stream flow and groundwater recharge. The magnitude of the impact of the climate

30 change was much more significant than the land use change on the streamflow and the groundwater

31 recharge. All the applied drought indices (SMD, WI, and $R D I)$ identified an increase in the severity of

32 the drought under future climatic change scenarios, especially under high emission scenario where the severity was the highest. Findings of the study are of great importance for Don Catchment that has 23 reservoirs for water supply. Some measures were suggested for sustainable management of the land and water resources in order to meet future water demand in the light of diminishing water supplies.

36 Key words: Climate change, Land use change; DiCaSM Hydrological model; Don Catchment;

37 Reconnaissance Drought Index (RDI); Soil moisture deficit (SMD) and land-use change. 


\section{Introduction}

Changes in the land surface hydrology are attributed to the collective effects of the changes in the climate, changes in vegetation, and the soil (Wang et al., 2018). Therefore, it is important to understand the impact of climate and land use changes on the water resources availability. In the UK, the land surface has changed slightly due to human interventions that mainly resulted in changes in land use for the food production, energy, housing and recreation. The recent land use changes are probably happening faster than at any other time in the human history, due to increase in demand for the natural resources, rapid changes in urbanisation, an increase in water demands for domestic and agricultural use. This is very significant for the UK where two-thirds of the land area is grassland. Approximately $14 \%$ of the UK is urban land which has significantly increased (by 300,000 hectares) since 1998 (Rounsevell and Reay, 2009). The other key land use changes are the agricultural land use practices which are driven by the farmers' decisions, which are economically driven by the availability of investment and subsidies (Shiferaw et al., 2009).

The UK and the study area (North East of England) have experienced a number of droughts, the most severe one is the one of 1976 (Marsh and Green, 1997). Annual precipitation in the region varies significantly, from $600 \mathrm{~mm}$ in the eastern lowlands to $2000 \mathrm{~mm}$ in western Pennine sites (Fowler and Kilsby, 2002). Contrary to the water supplies in the South-East region, water supplies in the North East depend on the reservoirs which fill during the winter months and are drawn down during the summer, this suggests that the water supplies in the region are more vulnerable to drought which is evident from the 1995 drought event (Fowler and Kilsby, 2002). The studied catchment, the Don is very significant for the water supplies in the region as there are 23 reservoirs within the catchment boundary which are recharged mainly during the winter months. Therefore, the main types of physical modification that affect the Don Catchment are the water storage and supply reservoirs, flood management structures, urbanisation and recreation including navigation (The Don Network, 2018).

The historic long-term record of the climate variables for the Sheffield area (part of the Don catchment area), covering the period from 1883 to 2015 , suggests a significant annual warming trend $\left(1.0{ }^{\circ} \mathrm{C}\right.$ per 
century), combined with an increase in annual precipitation (69 $\mathrm{mm}$ per century) with no significant trend in seasonal precipitation (Cropper and Cropper, 2016). There is a general perception that the urbanisation possibly added urban heat which contributed to the long-term warming trend which resulted in extreme precipitation events. This could potentially affect the water resources availability in the future and increase the drought risk, as water supplies within the catchment significantly depend on the reservoirs. Considering the historic climate and land use changes and likely changes in the future, it is important to study of the impacts of climate and land use changes on the studied catchment.

Although a number of studies including (Burke et al., 2010, Jackson et al., 2015, Wilby et al., 2015, Spraggs et al., 2015) have been carried out to identify the historic droughts in the UK using the observed data, less focus has been given to study the drought risk over catchment scale under different climate and land use change scenarios and their impacts on water resources. This study aims to address this issue in more detail and will also apply a number of indicators for the historic and future climate change which could potentially be used as drought indicators to identify meteorological, agricultural and hydrological droughts. The limited availability or access to the aquifers, the surface water reservoirs significantly contribute to the water supplies of the studied area. As the water available in the reservoirs is vulnerable to climate change, the reliability of water resources availability in the catchment could be at higher risk due to the climatic variability.

The objectives of this study is to quantify the impact of climate and land use changes on catchment water resources availability (surface and groundwater) and to develop suitable drought indicators to predict future drought events.

Findings of the study are importance for the Don catchment for managing the water abstraction, improvement in water infrastructure and planning for the future drought risk under climate change.

\section{Background of the studied catchment}

The Don Catchment (NRFA no. 27006) is in the North East of the country with a catchment area of 373 $\mathrm{km}^{2}$ (Fig. 1). The naturalised discharge (where the river-flow was adjusted to take into account 
91

Figure 1: The Don Catchment: boundaries, land use practices and location of the gauging station,

abstraction and discharge into the river) was obtained from Environment Agency. This was needed as streamflow is affected by presence of the 23 reservoirs, river abstraction for agricultural and industrial use, groundwater abstraction and by treated wastewater discharge. The key land uses of the catchment are: woodland which covers $15.8 \%$ of the catchment area, arable land, $6.1 \%$, grassland, $35.6 \%$, heather area, $18.9 \%$ and urban area, around $14.0 \%$ (Fig. 2). The catchment contains a moderate permeability bedrock which almost covers half of the catchment. Based on historical data, the average annual rainfall for the Don Catchment is around $1085 \mathrm{~mm}$ and average temperature $7.8^{\circ} \mathrm{C}$ for the baseline data, 1961 1990, the average annual rainfall for the studied period 1991-2012 was $1089 \mathrm{~mm}$ and the average temperature $8.5^{\circ} \mathrm{C}$. The Don catchment is important for drinking water as it supplies conurbations of South Yorkshire. Therefore, protecting drinking water sources now and in the future is essential. There are over twenty Yorkshire water reservoirs in operation.

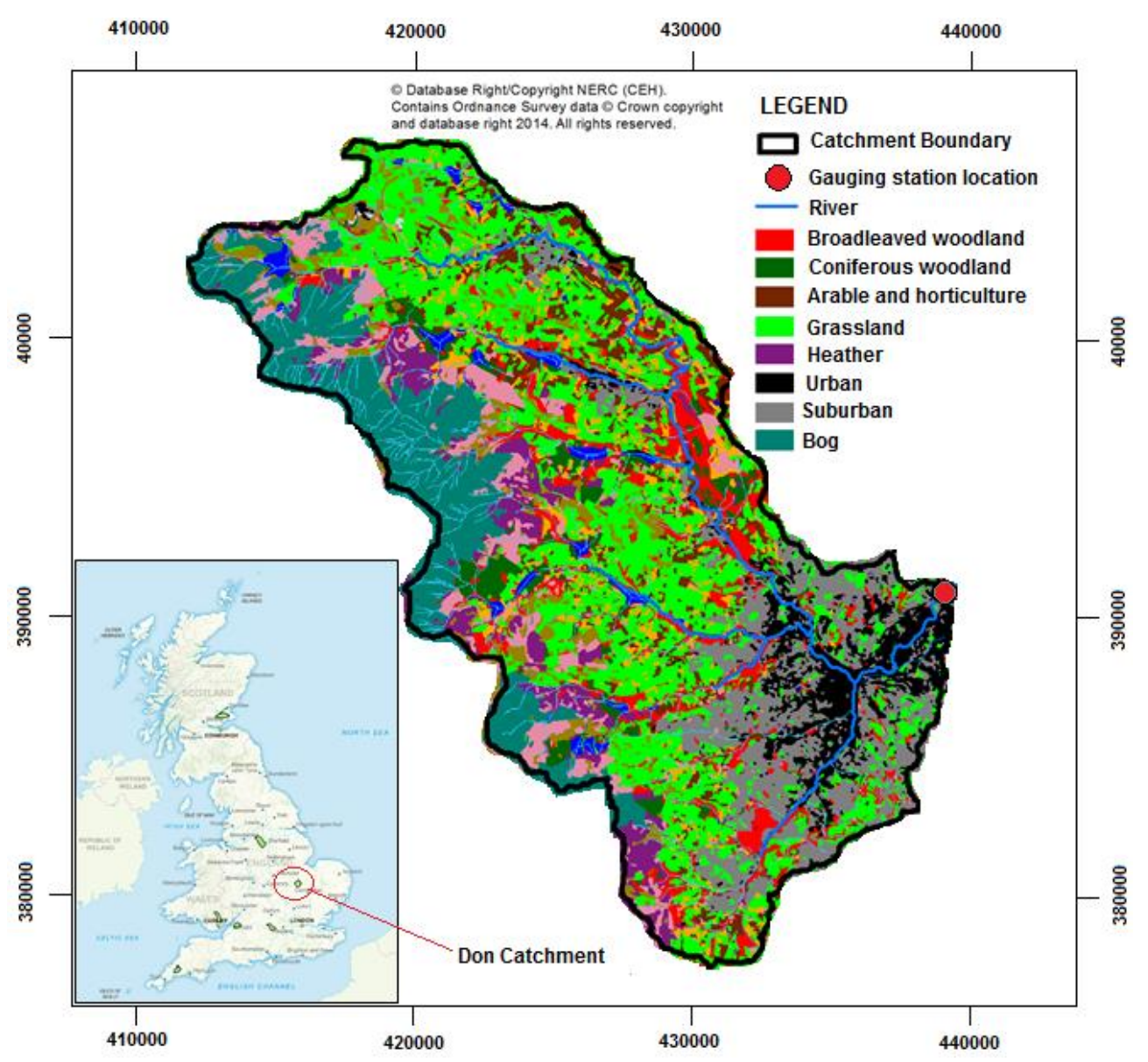
adapted from Morton et al. (2011). 


\section{Data, and the methodology}

\subsection{Historic climate, soil, river flow and future climate data}

The Distributed Catchment Scale Model, DiCaSM model was run on a daily time step and spatial scale of $1 \mathrm{~km}^{2}$ grid square area. The catchment area is $373 \mathrm{~km}^{2}$ covered by 435 grid squares (as not all the grid squares were covered in the catchment boundary), each of which has $1 \mathrm{~km}^{2}$ area. The model input requires a number of daily climatic variables including precipitation, temperature, wind speed, daily net radiation or total radiation and vapour pressure. Climate data were obtained from the Climate Hydrology and Ecology research Support System (CHESS) that accounted for the impact of changes in elevation on climatic data (Robinson et al., 2015, Tanguy et al., 2016). The historic continuous climatic variables and river flow data were available from 1961 until 2012. The catchment boundary and gauging station location data were available from Centre for Ecology and Hydrology (Morris et al., 1990, Morris and Flavin, 1994) and National River Flow Archive provided data for the daily river flow for the catchment (NRFA, 2014). The river and water body data were collected from the Centre for Ecology and Hydrology, 'Digital Rivers 50 km GB' Web Map Service (CEH, 2014). The UK Land cover data were obtained from the Centre for Ecology and Hydrology (Land Cover Map 2007, 25m raster, GB) Web Map Service (Morton et al., 2011). The soil data was obtained from the Cranfield University, (1:250 000 Soilscapes for England and Wales Web Map Service).

To study the impact of future climatic change on water supply systems, the UK Climate Projection Scenarios (UKCP09) was used using the joined probability factors and the UKCP09 weather generated data. In this study three 30-year periods: 2020's (2010-2039), 2050's (2040-2069) and 2080's (20702099) for the three greenhouse gas emission scenarios (low, medium and high) were considered. In UKCP09, Bayesian probability is used in which probability is derived from observations and outputs from a number of climate models, all with their associated uncertainties. The UKCP09 provides monthly, seasonal and annual, probabilistic changes factors at $25 \mathrm{~km}$ by $25 \mathrm{~km}$ grid square resolution for precipitation and temperature (Table 1). The seasonal temperature shows an increase in emissions scenario and time, particularly in summer and autumn, whereas the precipitation is showing rainfall 
decreases in summer and increases in winter relative to the 1961-1990 'baseline' period. The weather generator, WG, of UKCP09 provides daily output data at a $5 \mathrm{~km}^{2}$ resolution for more climate variables such as vapour pressure and sunshine hours, in addition to rainfall and temperature. This data was downscaled using the weighing factors from (CHESS) methodology that accounted for the impact of changes in elevation on climatic data. The sunshine hours were converted into net radiation following the methodology of Allen et al. (1998). For the initial exploratory analysis, simplified change factors were derived from UKCP09 joint probability central estimates. The joint probability plot was used to generate seasonal climatic change factors (\% change in rainfall and change in temperature, $\pm{ }^{\circ} \mathrm{C}$ ) to apply as an input to the DiCaSM model.

Table 1: Probabilistic changes in temperature and precipitation for the Don Catchment under UKCP09 climate change scenarios (joint probability) under three emission scenarios and three selected time periods.

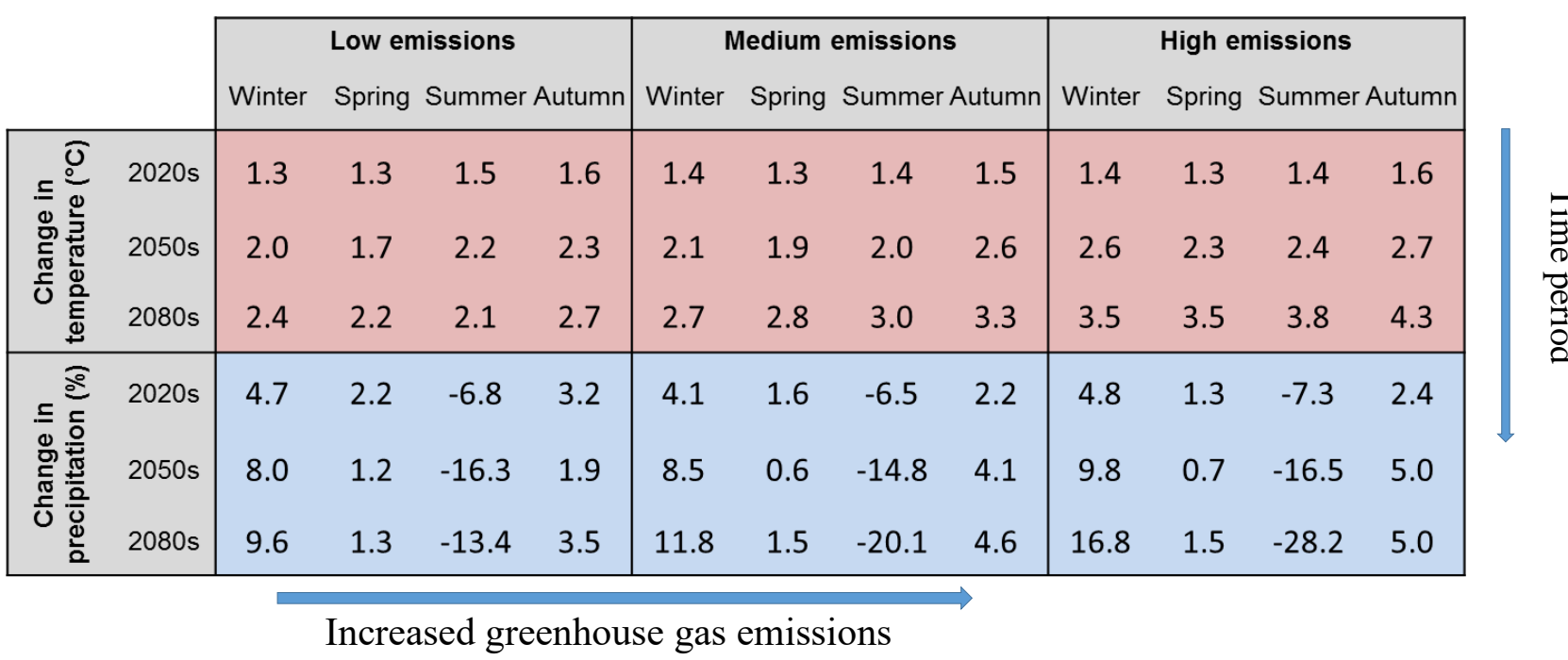

For the detailed weather generator simulations, 100 realizations of the daily time series data were generated in order to account for the uncertainty associated with the scenarios and alternative timing of events. This data was subject to bias correction, which was carried using the 'qmap' package in $\mathrm{R}$ statistical tool (Gudmundsson et al., 2012) using the 1961-1990 observation data as a reference period. This method has been successfully applied in drought studies including the study of Wang and Chen (2014). Forestieri et al. (2018) applied this bias correction method to study the impacts of climate 
change on extreme precipitation in Italy, De Caceres et al. (2018) subjected the daily climate models data to this approach and recently Hakala et al. (2018) applied this bias correction method to evaluate climate model simulations.

\subsection{Historic land use and its importance}

The studied Don catchment is not only significant for agriculture but also significantly contribute to the domestic water supplies. Water supplies in the catchment area come from the twenty-three reservoirs which are located within the catchment boundary. The low river flow can affect navigation, water supplies, and the aquatic ecosystem. Low flow also can result in river pollution due to the low dilution of the sewage effluent and can affect aquatic systems resulting in reducing the recreational activities within the catchment. Agriculture census data reveals that the key land-use in the area is grassland, heather and urban, with less than $10 \%$ of the catchment being agriculture (Fig. 2).

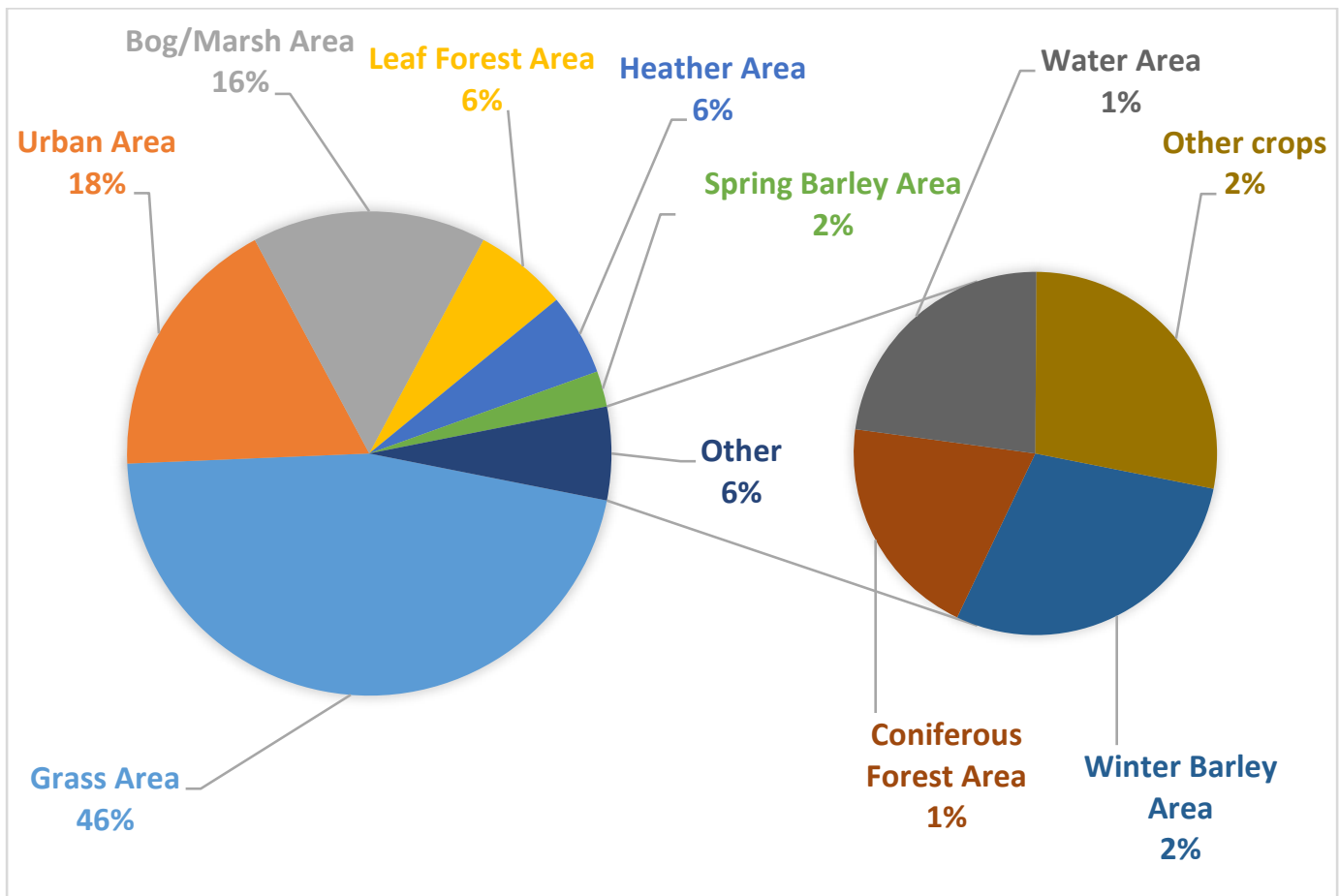

Figure 2: Current land use in the Don catchment

\subsection{Schematic representation of modelling work}

The schematic representation of the modelling work is shown in Figure 3 which shows the data sources used in the study. Both historic and future climatic variables data were used to generate the streamflow, 
groundwater recharge, net rainfall, potential and actual evapotranspiration, soil moisture deficit (SMD), wetness index $(W I)$ of the root zone and water losses due to interception. All these variables were directly or indirectly used to calculate the drought risk for both the historic period and for future climate change scenarios. Methodology about each used drought index is discussed later.

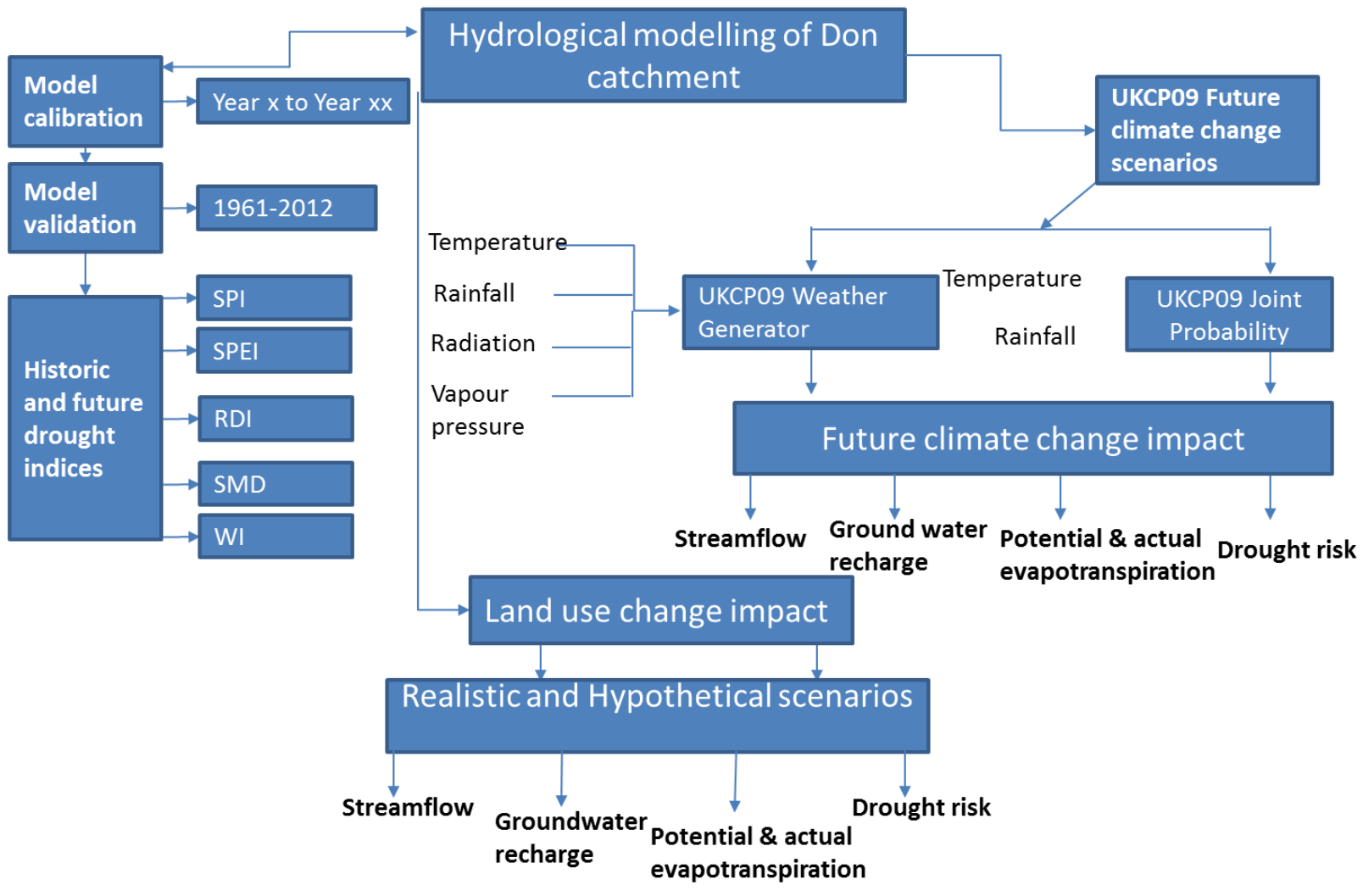

Figure 3: Schematic representation of the modelling application

\subsection{DiCaSM model input data and processes}

The hydrological DiCaSM is the acronym for the Distributed Catchment Scale Model was used to simulate the water balance of the catchment. The key input of the model are the meteorological data (temperature, rainfall, net radiation or total radiation, vapour pressure and wind speed), land use and vegetation (up to 20 land-uses can be assigned per each grid square), land altitude/elevation using the Digital Terrain Model, DTM, vegetation parameters and soil physical properties of each soil layer (saturated soil moisture content, soil moisture content at field capacity, soil moisture content at wilting point, saturated hydraulic conductivity). The model runs on daily time step and produces an output 

including spatially and temporally distributed series of potential evapotranspiration, actual evapotranspiration, soil water content, soil moisture deficit $(S M D)$, wetness index $(W I)$ of the rootzone, groundwater recharge, streamflow and surface runoff (Ragab and Bromley, 2010). The model is capable of simulating the impact of the changes in climate and land use on the catchment water balance.

The model also addresses the heterogeneity of input parameters of soil and land cover within the grid square using three different soil and plants algorithms (Ragab et al., 2010). In the model, runoff is routed between the low points of each grid square along the prevailing slope using the digital terrain model (DTM).

The model simulates the following processes, rainfall interception by land cover, evapotranspiration, surface runoff, infiltration, groundwater recharge, plant water uptake, bare soil evaporation and stream flows. Further details about the model are given in Ragab et al. (2010) and Ragab and Bromley (2010). For the studied catchment, the vegetation parameters (plant height, Leaf Area Index (LAI), and the canopy resistance were obtained from the UK-MORECS system (Hough et al., 1997). The model's efficiency (goodness of fit), measured during the model calibration and validation, was carried out using several efficiency indices, including Nash-Sutcliffe Efficiency (NSE), log of Nash-Sutcliffe Efficiency (log NSE) and Coefficient of Determination, $R^{2}$ as given below.

\subsubsection{Indices of measuring the model efficiency}

The calibration procedure consisted of adjusting the parameters related to stream flow calculations to achieve the best model fit, assessed using the NSE and log NSE of the stream flow. To estimate the model efficiency/goodness of fit, modelled and observed flow data were compared using a number of indices, including the Nash-Sutcliffe Efficiency (NSE) coefficient (Nash and Sutcliffe, 1970). NSE is the most widely used coefficient to assess the performance of stream flow (Gupta et al., 2009), the value of $100 \%$ indicating a perfect match.

$N S E=100-\frac{\sum_{i=1}^{n}\left(O_{i}-S_{i}\right)^{2}}{\sum_{\mathrm{i}=1}^{\mathrm{n}}\left(O_{i}-\overline{0}\right)^{2}}$ 
where $O_{i}$ and $S_{i}$ refers to the observed and simulated river flow data, respectively, and $\bar{O}$ is the mean of the observed data. Another index "Log NSE" is commonly used for low flows and based on the stream flow logarithmic values has also been considered, (Afzal et al., 2015, Krause et al., 2005). In addition, the model performance was also evaluated using the statistical indicators namely Coefficient of determination, $R^{2}$ as:

$$
R^{2}=\left\{\frac{1}{N} \frac{\sum\left[\left(y_{0}-\overline{y_{0}}\right] \overline{\left(\overline{y_{s}}-\overline{y_{0}}\right)}\right.}{\sigma y_{0}-\sigma y_{s}}\right\}
$$

where $y_{o}$ is the observed value, $y_{s}$ is the simulated value, $N$ is the total number of observations, $\bar{y}_{\mathrm{o}}$ is the average measured value, $\bar{y}_{\mathrm{s}}$ is the average simulated value, $\sigma y_{0}$ is the observed data standard deviation and $\sigma y_{s}$ is the simulated data standard deviation. The values of this index can range from 1 to 0 , with one indicating perfect fit.

\section{$\underline{3.5 \text { Identification of drought indices }}$}

The main drought drivers are temperature, radiation, wind speed, relative humidity / vapour pressure (Seneviratne, 2012). Figure 4 shows how these drought drivers can cause meteorological, agricultural and/or hydrological droughts. A number of drought indices can be used to identify drought events. The most common one is the Standardized Precipitation Index (SPI) (McKee et al., 1993). The SPI index represents the deviation of precipitation from the long-term average, negative values indicate below average "dry periods" and positive values indicate above average precipitation "wet periods". The index helps in finding different types of droughts, as precipitation is the key climatic variable upon which soil moisture deficit, stream flow and groundwater recharge depend. Therefore, it could easily be used to quantify the severity of both dry and wet events. Another drought index is the standardized precipitation evapotranspiration index (SPEI) which is a multiscale drought index, sensitive to global warming (Vicente-Serrano et al., 2010). This index has been widely applied in different parts of the world (Bachmair et al., 2018, Kunz et al., 2018) to the study meteorological and agricultural droughts and to study the impacts of drought severity on vegetation health (Bento et al., 2018). The equation used to calculate SPEI is based on (Thornthwaite, 1948): 
where $D i$ is the difference between the precipitation $(P)$ and the potential evapotranspiration $(P E T)$ for a particular month. The aim of applying this index was to measure the water surplus or deficit for the analysed month.

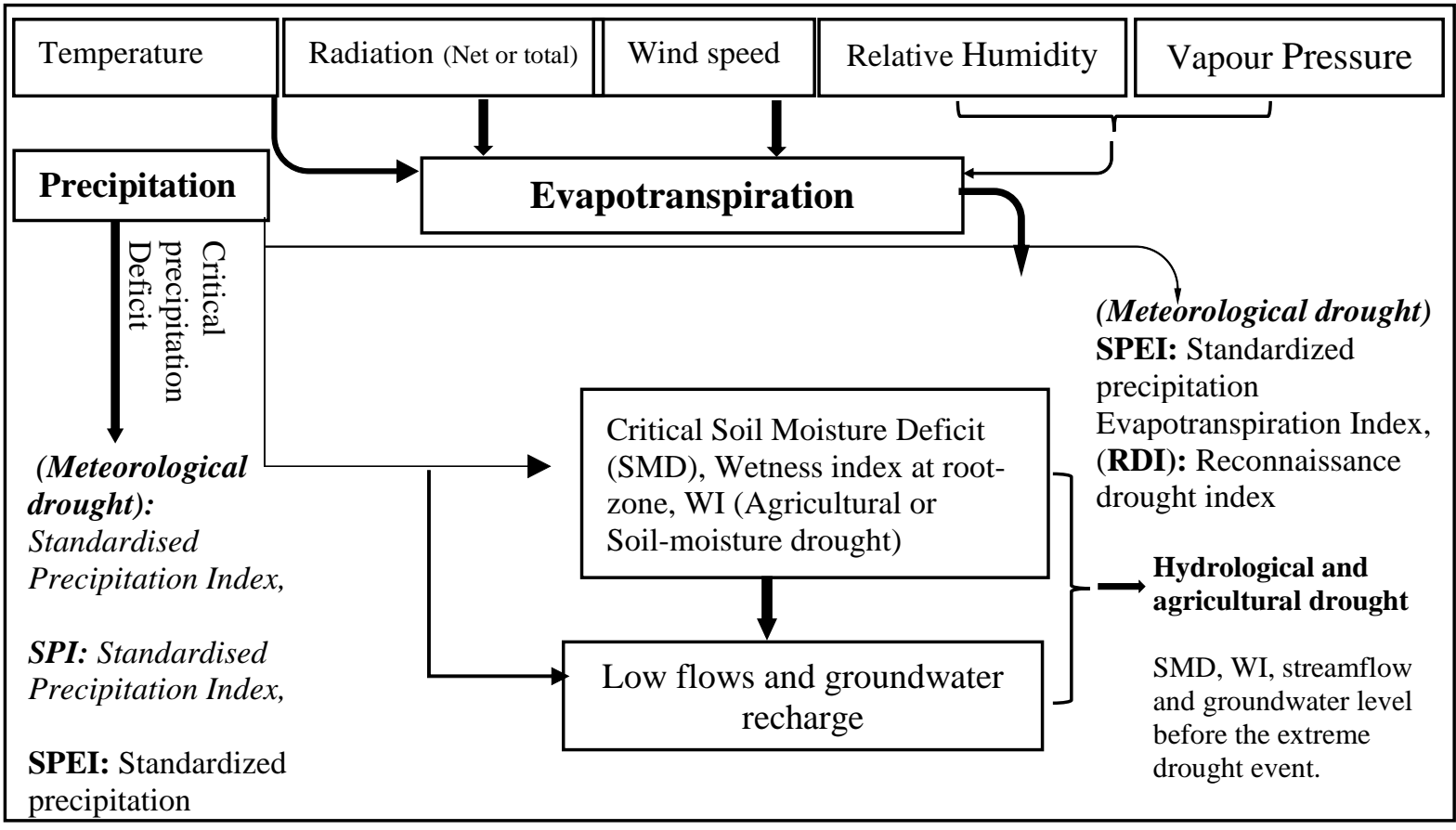

Figure 4: Key drought drivers of the meteorological, agricultural and hydrological droughts.

Like the SPI, a negative value shows dryness and a positive value shows wetness, relative to the longterm average. This drought index has been applied in a number of studies for example (Tirivarombo et al., 2018) and was used recently to study severity of extreme droughts events, like those of Cape Town, South Africa (Solander and Wilson, 2018). Another key drought index used in this study was the Reconnaissance Drought Index (RDI) which is based on Tsakiris et al. (2007). The standard RDI is calculated using the ratio of precipitation to potential evapotranspiration over a certain period. It is a good indicator for describing agricultural, hydrological and meteorological droughts. The Reconnaissance Drought Index $(R D I)$ was calculated as:

$a_{0}^{(i)}=\frac{\sum_{j=1}^{12} P_{i j}}{\sum_{j=1}^{12} \text { PETorAE }_{i j}}$ 
$R D I_{n}^{i}=\frac{a_{0}^{(i)}}{\overline{a_{0}}}-1$

$R D I_{s t(k)}^{i}=\frac{y_{k}^{(i)}-\bar{y}_{k}}{\widehat{\sigma} y k}$

where $P_{i j}$ and $P E T_{\mathrm{ij}}$ are the precipitation and potential evapotranspiration of the $j_{t h}$ month of the $i_{t h}$ hydrological year (starting from October), is $\bar{a}_{0}$ the arithmetic means of the $a_{0}$ calculated for the number of years. In the above equation $y_{i}$ is the $\ln \left(a_{0}^{(i)}\right), \bar{y}_{k}$ is its arithmetic mean and $\hat{\sigma} y k$ is its standard deviation. This drought index has been used in studies in different parts of the world, including Greece (Vangelis et al., 2013) and Iran (2015). This method is widely accepted and applied as it calculates the aggregated deficit between precipitation and the atmospheric evaporation demand. The method is directly linked to the climate conditions of a region and is comparable to the FAO Aridity Index (Tsakiris et al., 2007). In addition to the conventional way of calculating $R D I$, an adjusted $R D I$ was calculated using the net rainfall (gross rainfall minus rainfall interception losses by canopy cover) and actual evapotranspiration. Further to SPI, SPEI and RDI, two other drought indices were considered: the soil moisture deficit $(S M D)$ and the wetness index (WI) of the root-zone (Ragab and Bromley 2010). WI ranges from zero to 1 . The value of 1 means the catchment is at its maximum soil moisture content and 0 means the catchment at its lowest soil moisture content of the simulated period (Kalma et al., 1995). Wetness Index of the root zone (scaled soil moisture calculated as (current soil moisture - minimum soil moisture)/ (Maximum soil moisture - minimum soil moisture). Using a range of drought indices helps in identifying different types of droughts (meteorological, hydrological and agriculture), for example SPI for meteorological, RDI for hydrological and WI and $S M D$ for agricultural drought.

\section{Results}

The key six model parameters that were used to calibrate the model against the observed flow data were: the percentage of surface runoff flow routed to the stream, the catchment storage/time lag coefficient, an exponent function describing the peak flow, a stream storage/time lag coefficient, a base flow factor and the streambed leakage. The other factors on which model performance is also affected 
by are the soil hydraulic properties and the land cover parameters. The selected time period for calibration was run using a simple iteration algorithm for optimization in which each of the six stream flow parameters was assigned a range described by a minimum and a maximum value. Each range was divided into a number of steps and the number of total iterations is the product of multiplication of the steps of the six key parameters. The number of iterations for each parameter was assigned according to the parameter sensitivity, i.e. a higher number of iterations were assigned to parameters, which showed more sensitivity to the streamflow. The model calculates the Nash-Sutcliffe Efficiency value, NSE, ln NSE and $\mathrm{R}^{2}$ for each iteration. The model optimisation process helps in finding a good set of parameters that produces a good model efficiency value. Figure 5 (top) shows the model calibration during 20012012 where model efficiency, measured using the Nash-Sutcliffe Efficiency, was above $87 \%$ with less than two percent percentage error. The selected calibration period included a dry and a wet period in order to assess the model performance during both conditions.

The model performed well both during the rainy and dry events and responded according to soil hydrology status, i.e. during the soil moisture deficit period, a small rainfall event did not generate enough streamflow and during the heavy rainfall event, when the soil was at saturation during the winter months, the model responded extremely well. The model validation results during the drought period are shown in Figure 5 (bottom) for the 1970s decade, during this period model efficiency measured using the Nash Sutcliffe Efficiency was above 80\%, which shows good confidence in the used model efficiency parameters. The results of model prediction efficiency calculated in percentage as Nash Sutcliffe Efficiency, ln Nash Sutcliffe Efficiency or $\mathrm{R}^{2}$ values are shown in Table 2. The model calibration was carried out over a shorter period and validation over a number of 10 -year periods and over the entire study period. The overall model performance over the whole period, 1961-2012 was good, $(\mathrm{NSE}=83 \%)$. The correlation between the observed and simulated flow of different time periods is shown in Figure 6. The figure shows the model's capability to reasonably predict stream flows both during the model calibration and validation periods for both dry and wet periods. 
313 Table 2: Don Catchment model performance during the stream flow calibration and validation stages.

\begin{tabular}{|c|c|c|c|c|c|c|c|}
\hline Periods & NSE & $\begin{array}{l}\ln \\
\mathrm{NSE}\end{array}$ & $\mathrm{R}^{2}$ & $\begin{array}{l}\text { Square } \\
\text { root of } \mathrm{R}^{2}\end{array}$ & $\begin{array}{l}\text { Average } \\
\text { Modelled } \\
\text { flow } \mathrm{m}^{3} \mathrm{~s}^{-1}\end{array}$ & $\begin{array}{l}\text { Average } \\
\text { Observed } \\
\text { flow } \mathrm{m}^{3} \mathrm{~s}^{-1}\end{array}$ & $\begin{array}{l}\% \\
\text { Error }\end{array}$ \\
\hline $2001-2012^{*}$ & 87.08 & 73.1 & 0.87 & 0.93 & 4.86 & 4.73 & 2.61 \\
\hline $1991-2000$ & 87.03 & 79.1 & 0.88 & 0.93 & 5.10 & 5.18 & -1.60 \\
\hline 1981-1990 & 83.13 & 76.4 & 0.84 & 0.91 & 5.17 & 5.13 & 0.81 \\
\hline $1971-1980$ & 82.21 & 66.1 & 0.83 & 0.91 & 4.68 & 4.90 & -4.63 \\
\hline $1966-2012$ & 83.06 & 73.0 & 0.84 & 0.91 & 5.06 & 5.08 & -0.60 \\
\hline
\end{tabular}




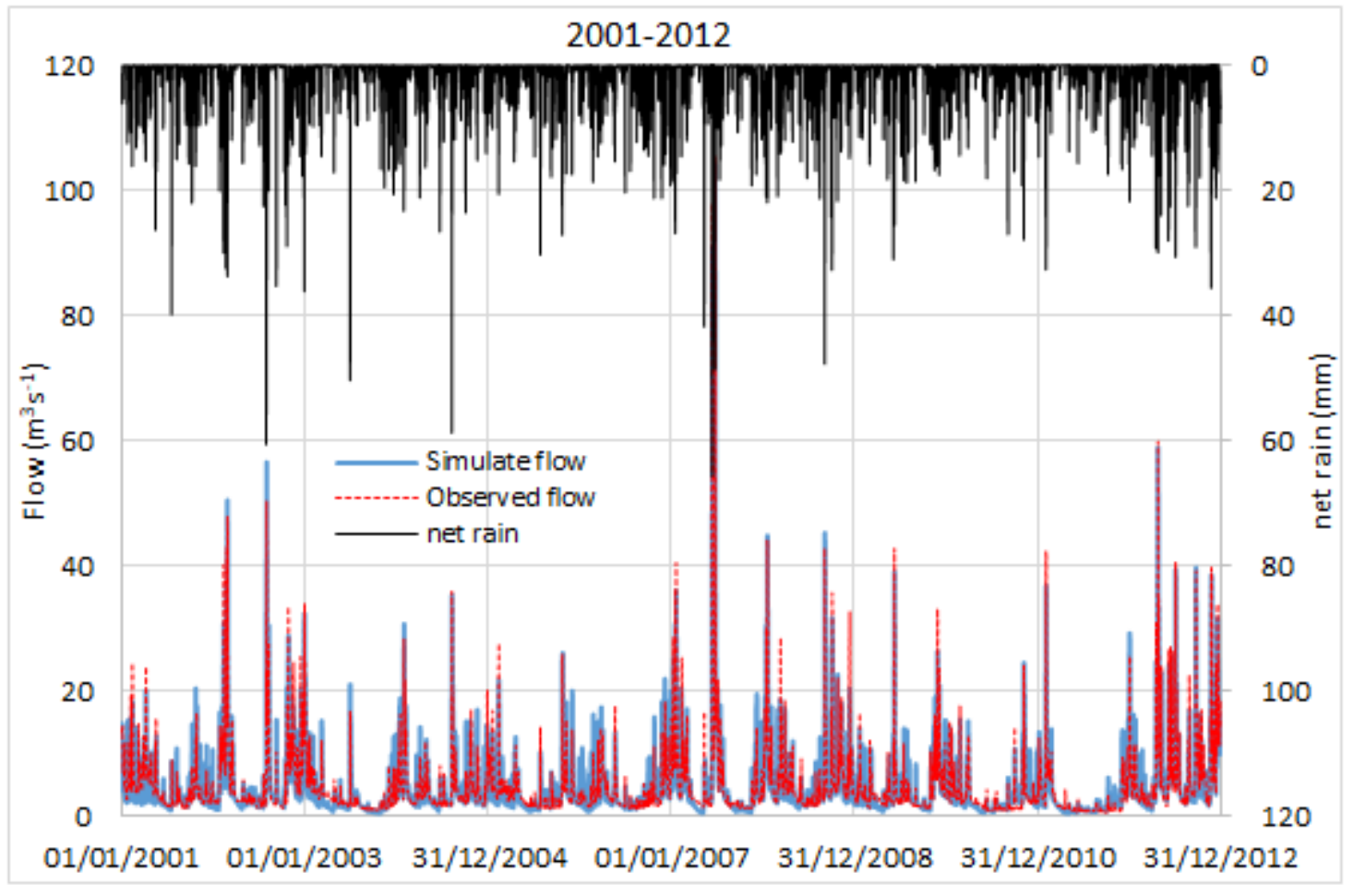

317

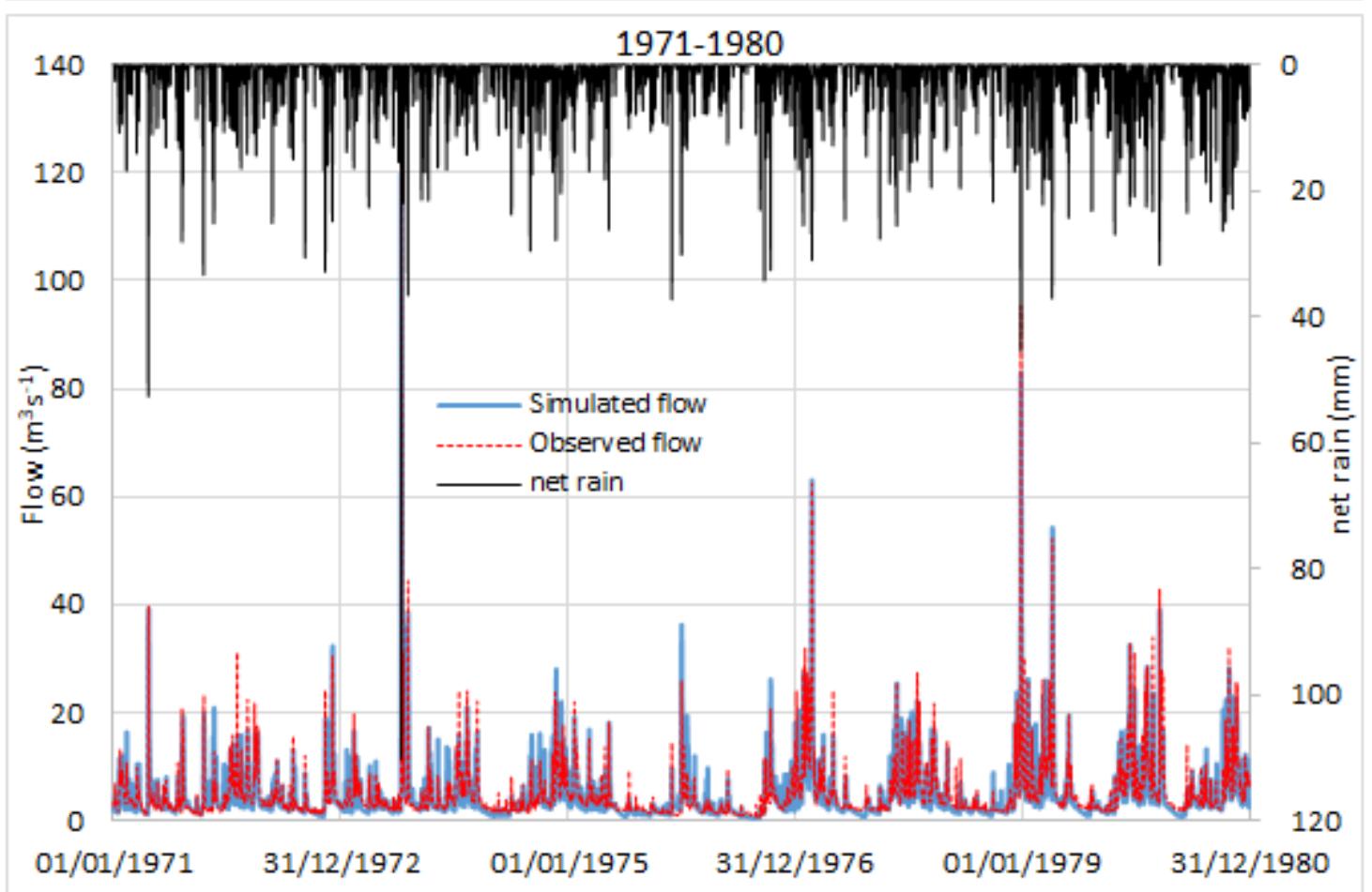

Figure 5: Don Catchment calibration (2011-2012) and validation (1971-1980) period. 

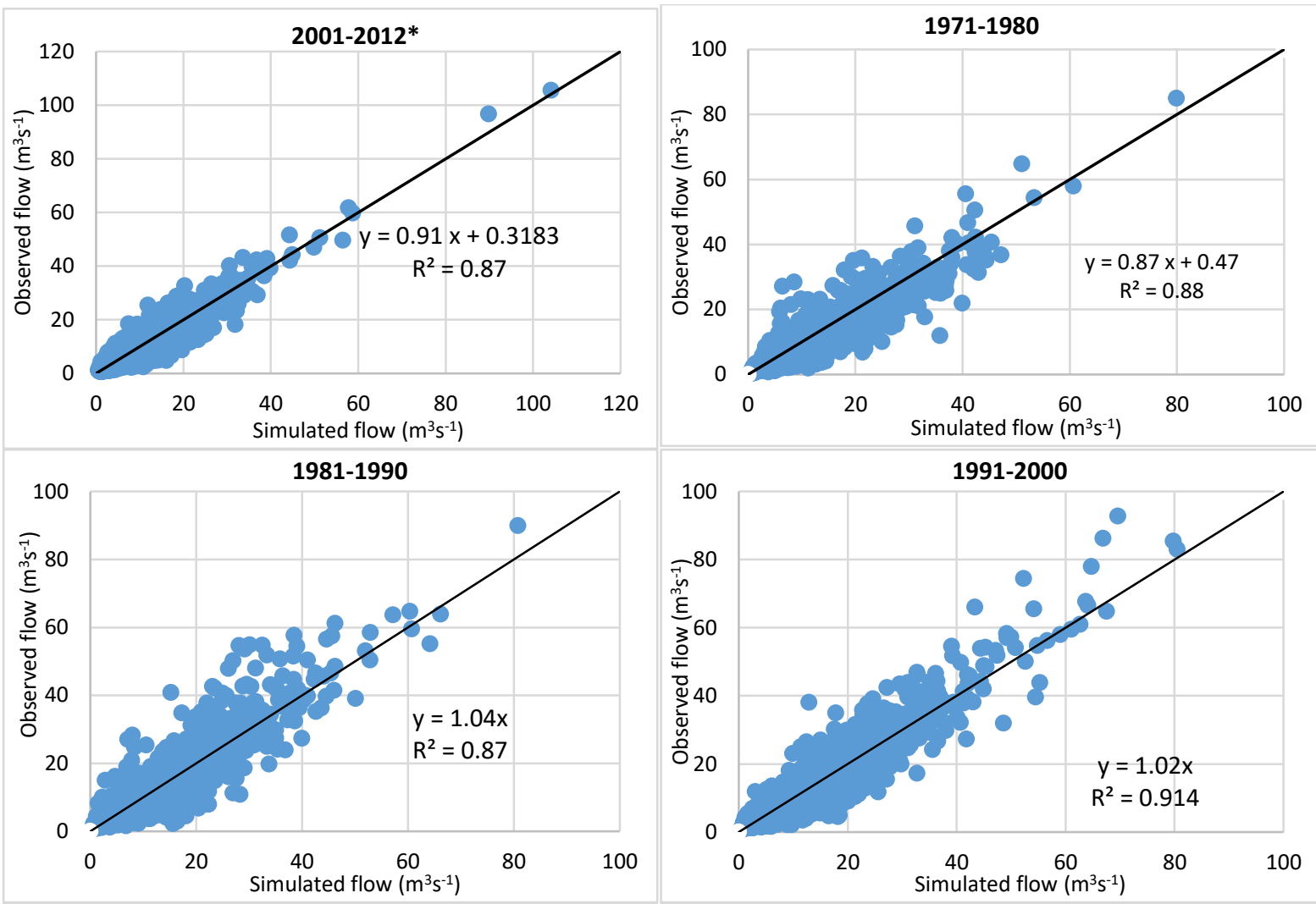

322
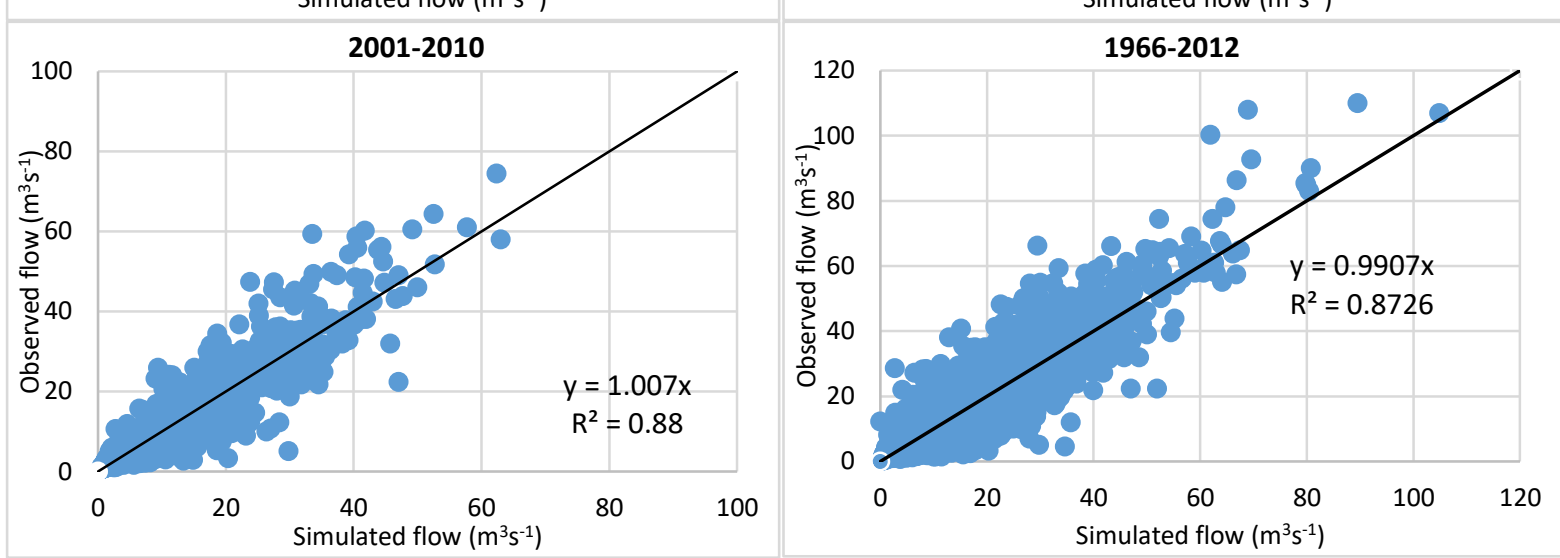

Figure 6: Relationship between the observed the simulated flow during the model calibration and model validation over a decadal time scale and over the entire period.

\subsection{Identification of historic droughts}

327 4.2.1 The standardized precipitation index (SPI) and Standardized Precipitation Evapotranspiration 328 Index (SPEI)

329 The SPI is the most commonly used drought index to describe the deviation of the precipitation from 330 the average precipitation. The SPI index scale values mean: above 2.0 extremely wet, $1.5-1.99$ very 331 wet, $1.0-1.49$ moderately wet, -0.99 to 0.99 near normal, -1.0 to -1.49 moderately dry, -1.5 to -1.99 
severely dry and -2.0 and less, extremely dry (McKee et al., 1993). The SPI and SPEI time series are shown in Figure 7 which also illustrates that the SPEI has shown higher severity for both dry and wet events, more clearly for the 1970s drought. Both indices picked up all the drought events which took place in the Don Catchment between 1961 and 2012.

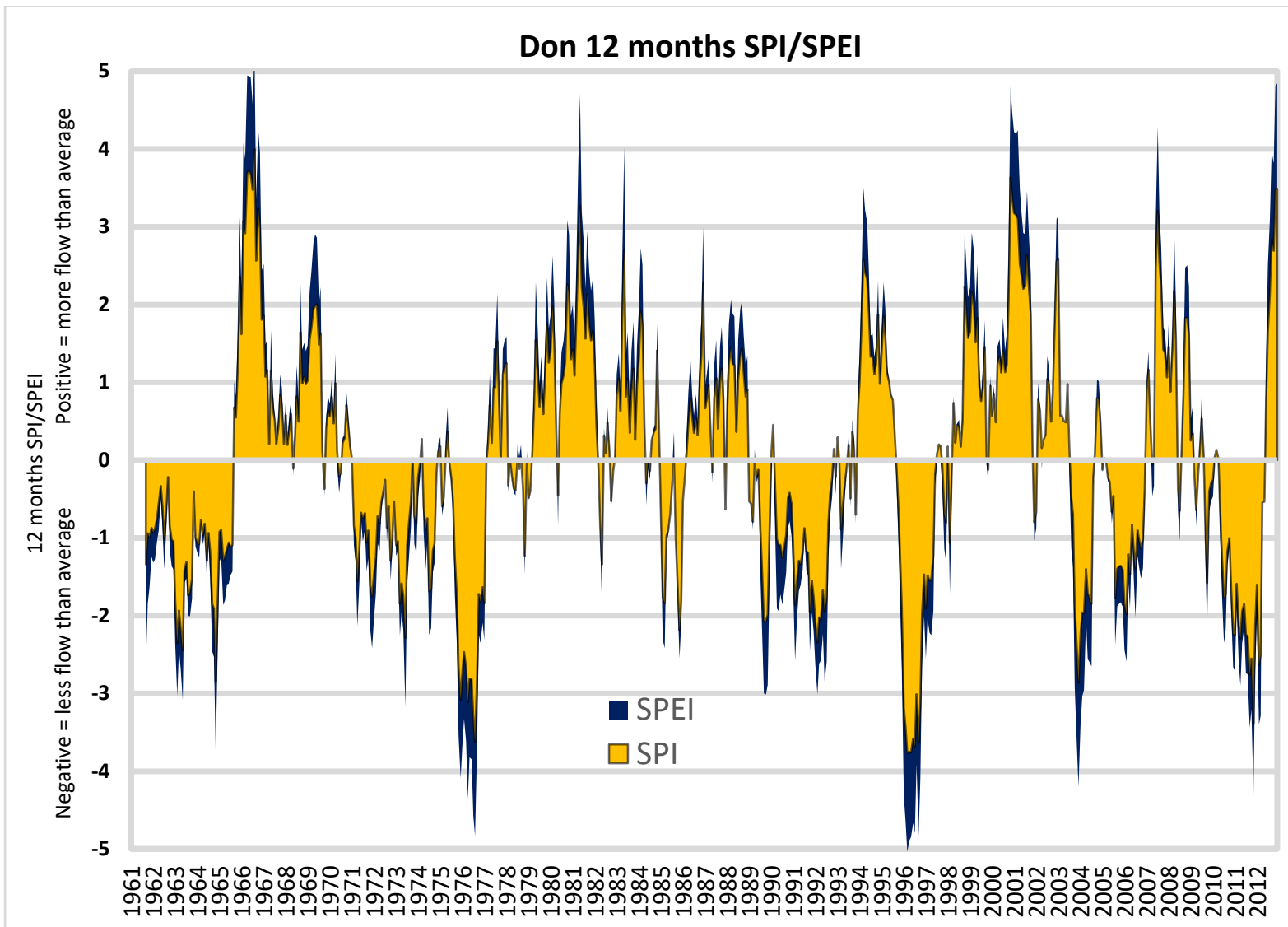

Figure 7. The standardized precipitation index (SPI) and standardised precipitation potential evapotranspiration index (SPEI) of the Don Catchment from 1961 to 2012.

As the evapotranspiration calculation in the model is dependent on climatic data as well as on a number of soil and plant parameters, the SPEI is expected to better represent the severity of the drought. Both SPI and SPEI indices crossed over the 'extremely severe' drought level during the most well-known 1970s drought which affected most parts of the UK and Europe. The catchment experienced two extreme drought events which took place in the mid-1970s and the mid of 1990s. These drought indices show that the Don Catchment was subjected to drought events which significantly affected Southern England, the Anglian regions, Southern and Eastern England and the Midlands (Parry et al., 2016). The drought termination rate showed a west-east divide in 1995-1998, which was more apparent in the 
Midlands and Southern and Eastern England. This is evident from both the SPI and SPEI indices, which crossed over the 'extreme drought' level during both the 1970s and the 1990s droughts. Not only the occurrence of the drought events (frequency) but also the duration and drought strength significantly affect the streamflow and the groundwater recharge.

Therefore, the SPI and SPEI indices could be used as good indicators for the meteorological and hydrological drought. The SPI and SPEI indices over 52 years elucidated the successive dry events, like those occurred in the 1970s and the 1990s. The SPI and SPEI indices also help in identifying smaller magnitude drought events, or drier periods, which took place in the late 1960s, early 1990s, in 20052006 and in 2010. The magnitude of the severity of drought was considered as severe in the mid-1970s, in 1976 and in 1996 when SPI and SPEI indices were well below -2, 'extreme drought' level.

\subsubsection{Reconnaissance Drought Index (RDI)}

Figure 8 shows the comparison between the adjusted RDI and the classical RDI. Both picked up all the drought events, which were detected by the SPI. However, the advantage of applying the RDI over SPI is that it does not rely on one factor only, i.e. precipitation. The adjusted RDI showed slightly different severity levels, especially during the extreme drought events. In addition, there is a strong correlation between the two ways of calculating the RDI and the SPI/SPEI. Figures 7 and 8 show that the extreme drought conditions of 1976, 1996 and 2006 was picked up similarly by both SPI/SPEI and RDI/adjusted $R D I$. Drier than average events (SPI/SPEI less than $-10 \%$ or $R D I$ less than -1 ) were also observed in 1964, 1975, 1990, 1996, 2003, 2005, 2011. Both drought indices also picked up extreme drought events which took place in 1976, 1989 and1996. However, the severity of the drought event was slightly higher when applied reconnaissance drought index using the gross rainfall and the potential evaporation in most of the cases. Based on both types of RDIs and SPI/SPEI drought indices, the total percentage of wet years were higher than total percentage of dry years. 


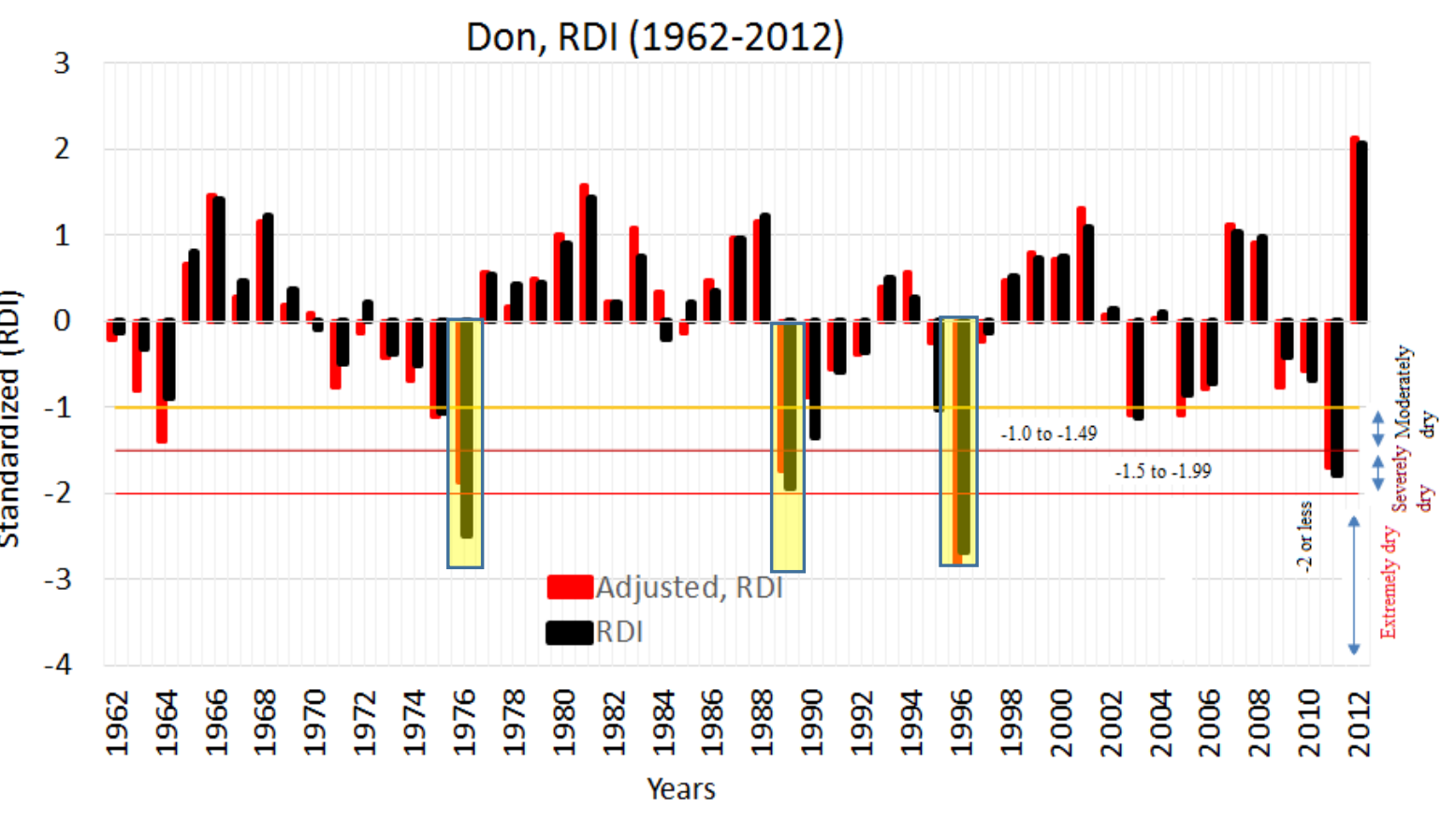

371 Figure 8: Standard RDI (Reconnaissance drought index) based on potential evapotranspiration and total rainfall and the adjusted RDI, calculated using net-rainfall and actual evapotranspiration, for the Don Catchment during the 1962-2012 period.

4.2.3. Soil moisture deficit, $S M D$ and Soil Wetness Index, $W I$ as a drought indicator

402 In addition to the SPI/SPEI and RDI drought indices, which are more commonly used to predict 403 meteorological and hydrological droughts, two other drought indices soil moisture deficit and wetness 404 index of the root-zone, which are more appropriate for the agriculture drought, were applied in the 405 study. For agriculture drought, the soil moisture deficit, SMD and the wetness index, WI of the rootzone are more appropriate (Fig. 9). The wetness index, WI represents how relatively wet or dry the catchment is over the period. 


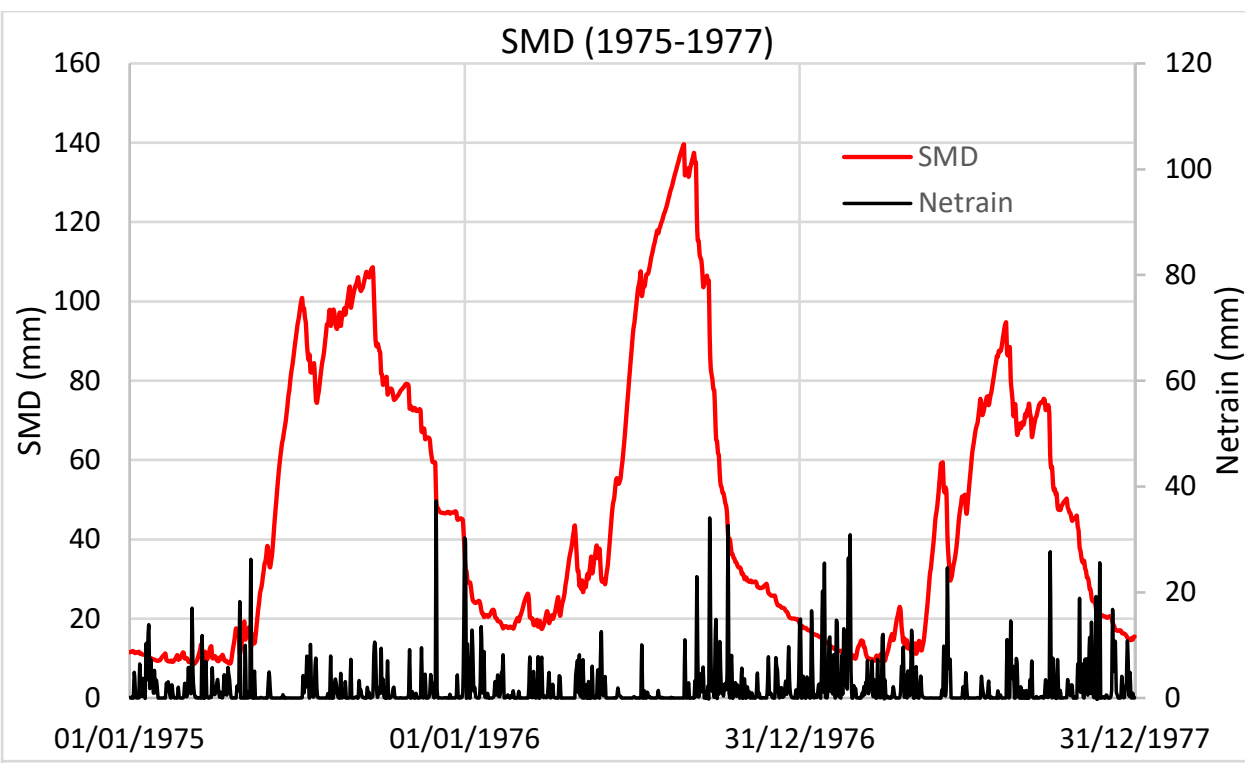

Wetness Index (1996-1998)

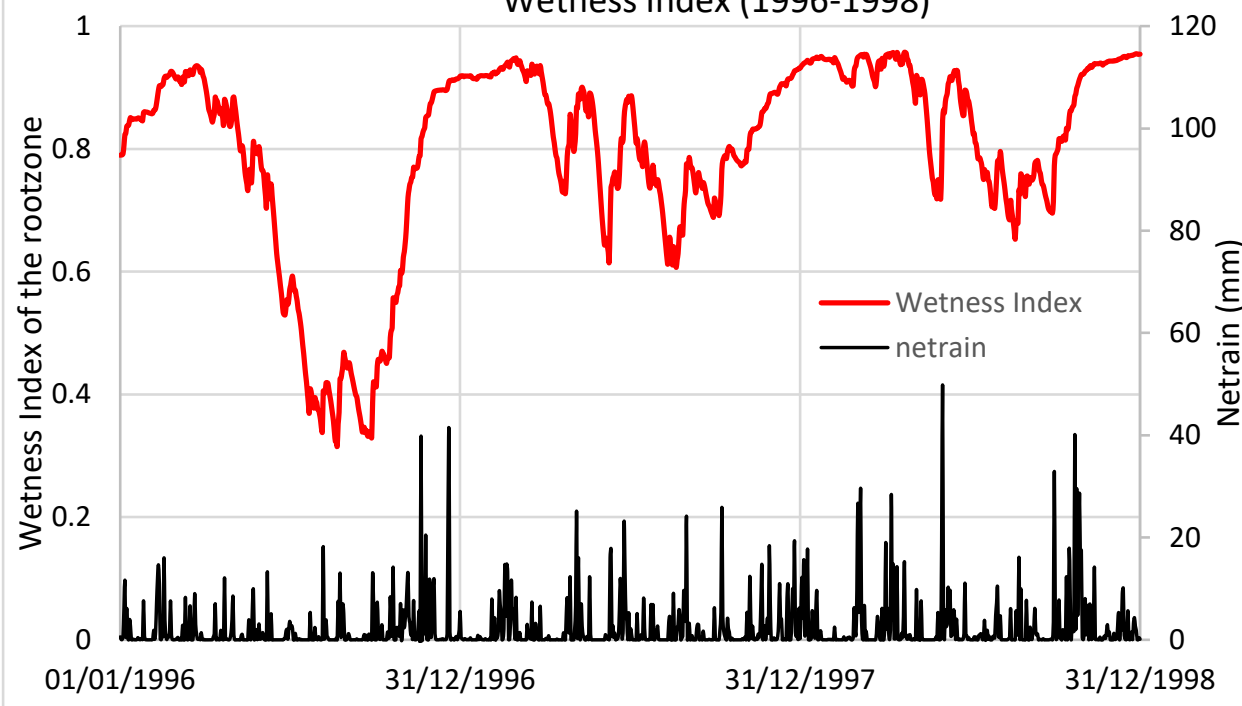

Figure 9: Soil moisture deficit from 1975 to 1977 (top) and Wetness Index of the root-zone from 1996 to1998 (bottom) for the Don Catchment.

The WI is a scaled soil moisture status that accommodates the spatial variability of soil types, elevation, vegetation cover, etc. across the catchment. The Soil Moisture Deficit, SMD represents the deviation of soil moisture from the soil moisture at field capacity. Here zero means, the catchment's soil moisture is at field capacity level. The deviation gets larger when the soil moisture starts to fall below the field capacity, especially during summer and during drought periods. Examples of both indices are shown in Figure 9 which clearly shows the significant change in soil moisture indicators WI and SMD during the dry summer months, especially during the extreme droughts in 1975 and 1976 and the recovery in 1977 for the SMD. In the dry summer months of 1975 , the soil moisture deficit exceeded $100 \mathrm{~mm}$ and during the 1976 dry summer period, soil moisture deficit was over $140 \mathrm{~mm}$. The figure also shows the severity 
of the dry spell as a result of the continuation of the dry seasons including the 1975-1976 winter months as the $S M D$ did not drop down to zero, whereas in the 1977 winter months, above average winter rainfall brought the $S M D$ back to zero after persistent rainfall events during the 1977 winter months. It can also be seen that the WI dropped below the winter value of 1.0 to 0.3 during the extreme drought of the summer of 1976 and mirrored the other drought indices including the SPEI/SPI and the RDI.

\subsection{Future climate change impact on the water resources}

\subsubsection{Changes in streamflow}

The future climate change scenarios (UKCP09) suggest an increase in temperature under all emission scenarios and a decrease in rainfall, during the summer months (Table 1). To study the impact of climate change on the hydrology of the Don catchment, the future climate projections were derived using two approaches based on UKCP09 outputs: simplified change factors based on joint probability data and the weather generator data. Using the joint probability approach, nine scenarios (three time periods and three emission scenarios) were investigated. The seasonal climate change factors (relative to the baseline data, 1961-1990) of temperature ( \pm change in ${ }^{\circ} \mathrm{C}$ ) and rainfall (\% change in rainfall) at the most likelihood (central estimate) probability level were input into the DiCaSM model and applied on the 1961-1990 baseline climate data (Table 1).

A significant change in streamflow was observed using both approaches. The simplified change factor (joint probability) approach suggests that streamflow is likely to increase in winter (December, January, February) by up to $10 \%$ in the 2080 s under high emission scenarios due to an increase in winter rainfall. Similar results were also observed using the weather generator data for the winter months, but the decrease in streamflow was not that significant (Fig. 10). This is of greater significance for the Don Catchment which significantly contributes to the water supplies in the region as there are 23 reservoirs within the catchment boundary which are recharged mainly during the winter months.

In the spring (March, April, May) season, there is little difference in the change in streamflow under three emission scenarios and three selected time periods. With an exception in the 2020 s, under low and 
medium emission scenarios, where the streamflow in spring is likely to decrease by $-2.11 \%$ to $-5.45 \%$ under low emission scenarios, $-1.48 \%$ to $-4.82 \%$ under medium emission scenarios and within $-1.39 \%$ to $-4.45 \%$ under high emission scenarios, relative to the baseline period. During the spring season, the evaporation is low relative to the precipitation and the soil is more saturated except during the latter part of spring (Fig. 10).

During the 2020s period, in summer, a significant decrease in streamflow is projected under all emission scenarios. In the 2020 s, the summer streamflow is likely to decrease, by 13 to $15 \%$ using the joint probability approach, whereas under the weather generator only a small decrease of up to $4.5 \%$ is projected. In 2050s a significant decrease of 12.75 to $17.86 \%$ relative to baseline period is projected using the weather generator data, whereas under the joint probability, a decrease is projected from 27 to $29 \%$ with no significant variation under different emission scenarios. During the summer season in the 2080 s, using the joined probability approach, the stream flow is likely to decrease by 24 to $42 \%$, whereas using the weather generator data, streamflow is likely to decrease by 16.05 to $25.5 \%$, depending on the emission scenario.

The severity of the change, particularly during the summer season, could lead to very low stream flows, possibly leading to a high risk of inadequate domestic, industrial and agricultural water supply. The latter is more significant for the Don catchment, as river water abstraction is very significant. The streamflow is likely to decrease in the summer season because the soils are not saturated like they are during winter and spring, as a results soil moisture deficit is likely to increase. The combined effect of decreasing rainfall with the increasing temperature could result in higher evapotranspiration during the summer season, which in turn could result in reduced flow especially under high emission precipitation in autumn and spring (enhanced by higher evaporation), saturated conditions will occur less frequently, and precipitation events will be less likely to generate high runoff flow flows. 


\begin{tabular}{|c|c|c|c|c|c|c|c|c|c|}
\hline & \multicolumn{3}{|c|}{ Low emission } & \multicolumn{3}{|c|}{ Medium emission } & \multicolumn{3}{|c|}{ High emission } \\
\hline & 2020s & $2050 s$ & 2080s & $2020 s$ & $2050 s$ & $2080 s$ & $2020 s$ & $2050 s$ & $2080 s$ \\
\hline
\end{tabular}

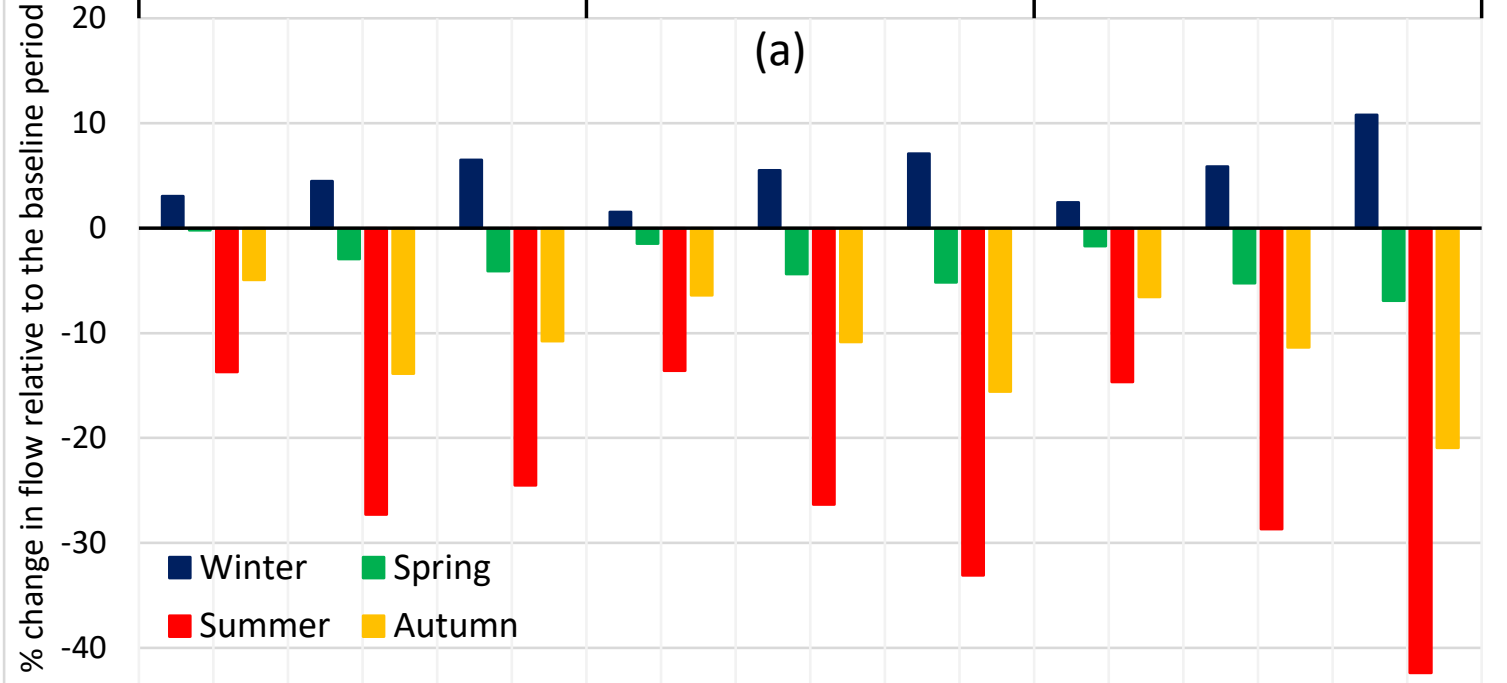

473

$-50$

474

475

476

477

(b)

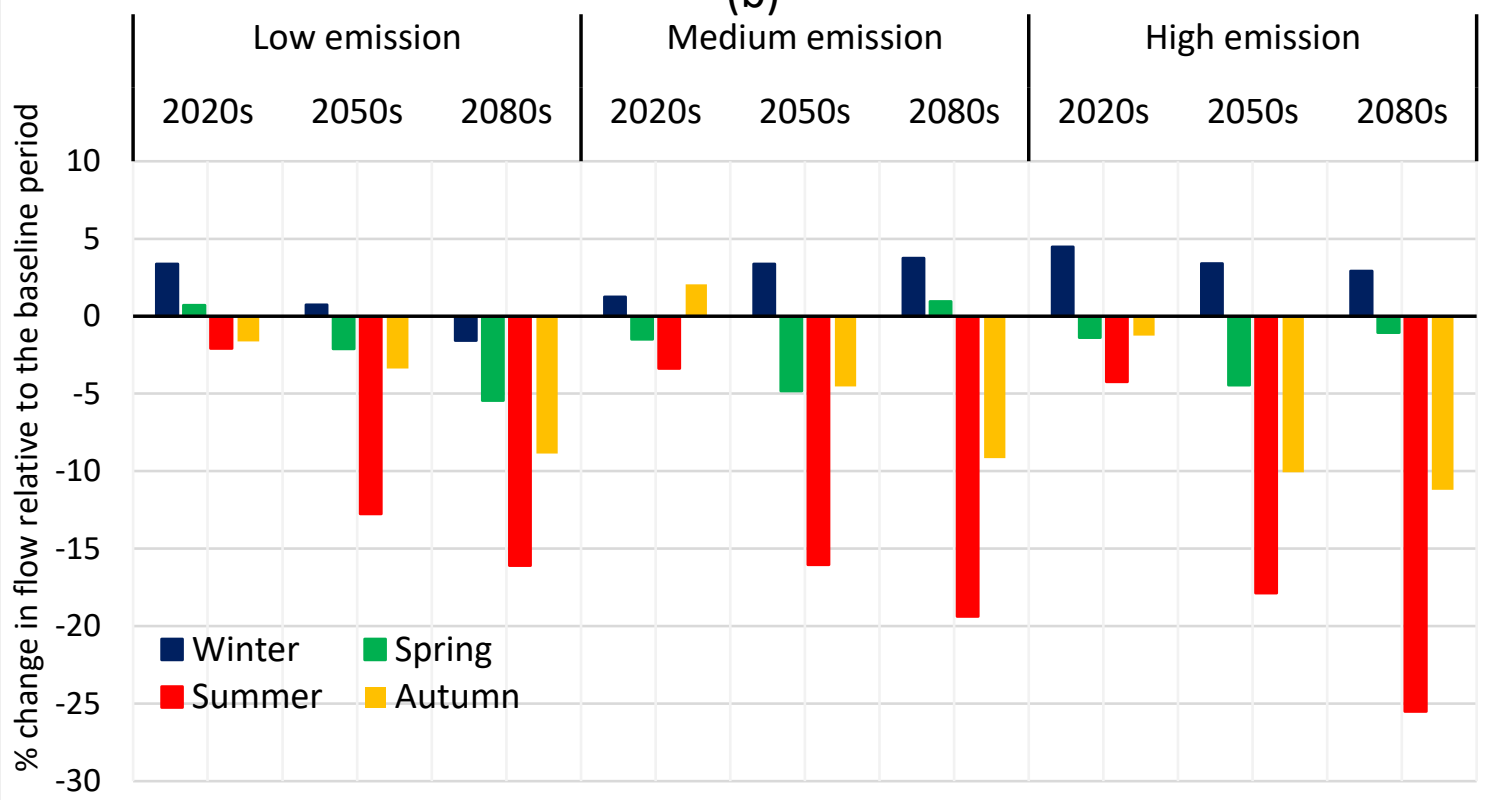

Figure 10: Percentage change in streamflow relative to the baseline period (1961-1990) over seasonal scale under low, medium and high emission scenarios for the 2020s, 2050s and 2080s, under UKCP09 joined probability (a) and under UKCP09 weather generator (b).

In autumn, streamflow is likely to decrease slightly under low and high emission scenarios, and a slight increase under medium emission scenarios in the 2020s. Overall, there is not much variation among the emission scenarios in the 2020s. However, in 2050s, more significantly under medium and high emission scenarios, up to $10 \%$ decrease under both joint probability and the weather generator approach 
was observed. No significant change in rainfall is projected under medium and high emission scenarios, but an increase in temperature and reduced rainfall in summer would lead to higher soil moisture deficit during both the summer and autumn seasons, combined by an increase in autumn temperature this would result in reduced streamflow in autumn due to higher water losses by evapotranspiration. The simplified change factor (joint probability) showed slightly higher change compared to the weather generator as joint probability method only consider two climate variables (rainfall and the temperature).

Overall, in all seasons, the severity of the change in streamflow more particularly during the summer season could lead to very low stream flows, possibly leading to a high risk of inadequate domestic, industrial and agricultural water supply. The latter is more significant for the Don catchment as there are twenty-three reservoirs within the catchment, which significantly contribute to the water supply systems.

\subsubsection{Changes in groundwater recharge}

The analysis using the weather generator and joint probability, under all emission scenarios and for the selected time periods showed that the groundwater recharge would decrease, with some exceptions under weather generator in the 2020s more significantly under high emission scenarios when groundwater recharge increased by $4.32 \%$ compared to the baseline period (Fig. 11b). The increase in winter precipitation would be counterbalanced by the higher water losses by the increased evapotranspiration (due to increased temperature) which resulted in a small increase in groundwater recharge in comparison to the baseline period in the 2020s. The groundwater recharge projections under joint probability suggest that the groundwater recharge is likely to decrease from 3.39 to $11.25 \%$ under all emission scenarios during the winter months (December, January, and February). Without exception, groundwater recharge decreased for the three selected time periods, but the decrease will be slightly less under low emission scenarios, compared to the medium and high emission. This is due to a smaller increase in precipitation under low emission scenarios. Considering the change in precipitation under all emission scenarios, the likely increase in the groundwater recharge is lower than expected, due to losses by evapotranspiration that causes a decrease in stream flow and groundwater recharge in all 
seasons. Other factor which could reduce the groundwater recharge in all seasons, is that the winter

509 precipitation is expected to come as extreme events and over a short period of time, as reported in

510 Alexander et al. (2005). The groundwater recharge is also likely to decrease in spring due to milder

511 increase in spring temperature and the insignificant change in precipitation.

512 A significant decrease in groundwater recharge is projected in summer months due to increasing 513 temperature and a decrease in precipitation, which result in higher water losses due to 514 evapotranspiration, higher soil moisture deficit and lower the groundwater recharge. Using joint 515 probability, the groundwater recharge is likely to decrease by over $60 \%$ under medium emission 516 scenarios in the 2080 s and up to $75 \%$ under high emission scenarios. The percentage change in 517 groundwater recharge was not that high when using the weather generator data. The highest decrease 518 in summer groundwater recharge projected for the 2080s is likely to be over $40 \%$, compared to the 519 baseline period. Such a significant decrease in groundwater recharge could be the result of increased 520 soil moisture deficit. Under all emission scenarios and observed time periods, the groundwater recharge 521 is likely to decrease by $-38 \%$ to $-58 \%$ under joint probability and $-10 \%$ to $-30 \%$ under the weather 522 generator under the low emission scenarios; while under medium emission scenarios the decrease in 523 groundwater recharge would fall within $-38 \%$ to $-67 \%$ with joint probability and $-13 \%$ to $-35 \%$ with 524 the weather generator; the highest decrease is projected under high emission scenarios with -39\% to $52576 \%$ under joint probability and $-13 \%$ to $-40.2 \%$ under the weather generator, all changes are in 526 comparison to the baseline period. 
(a)

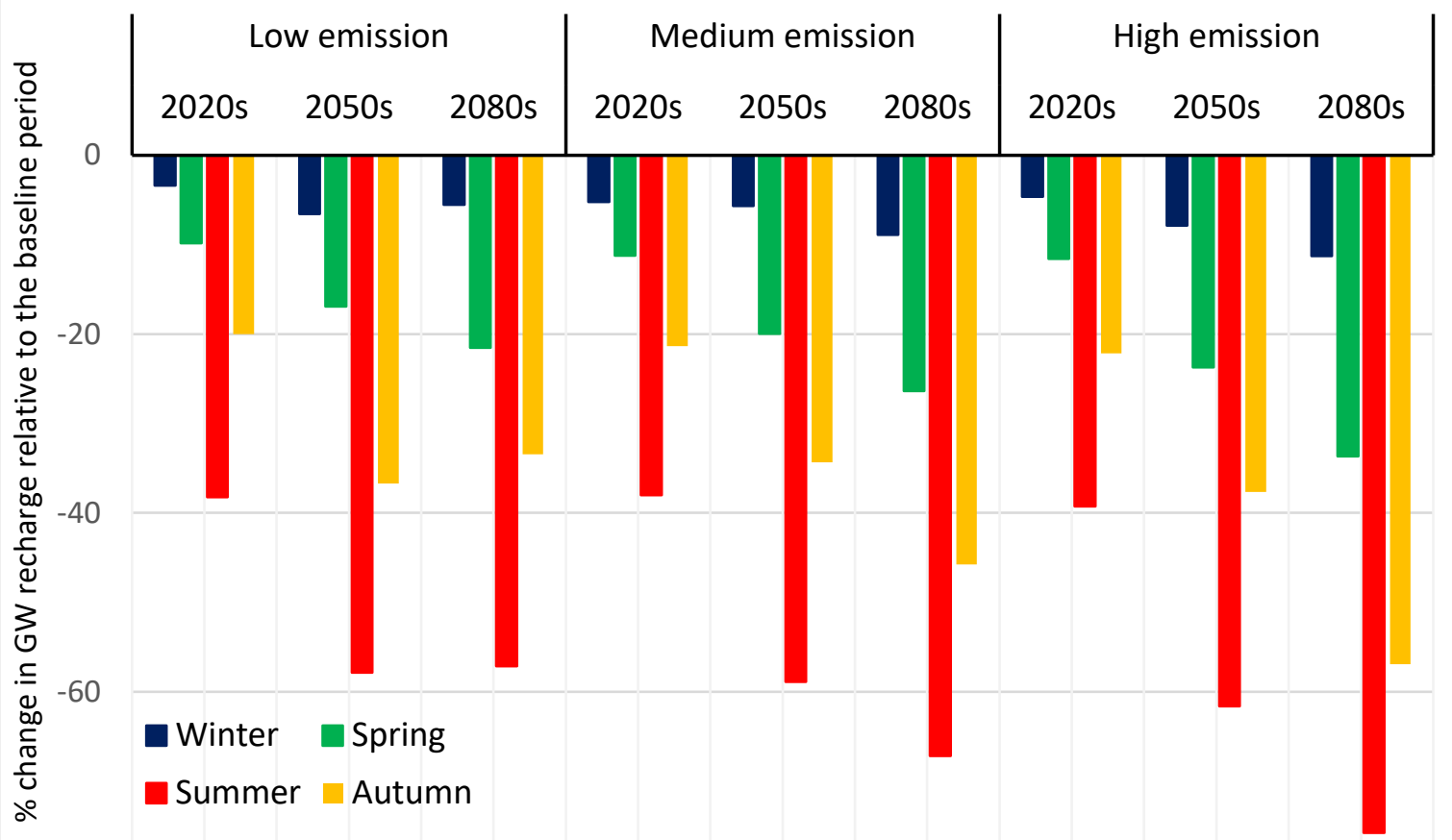

(b)

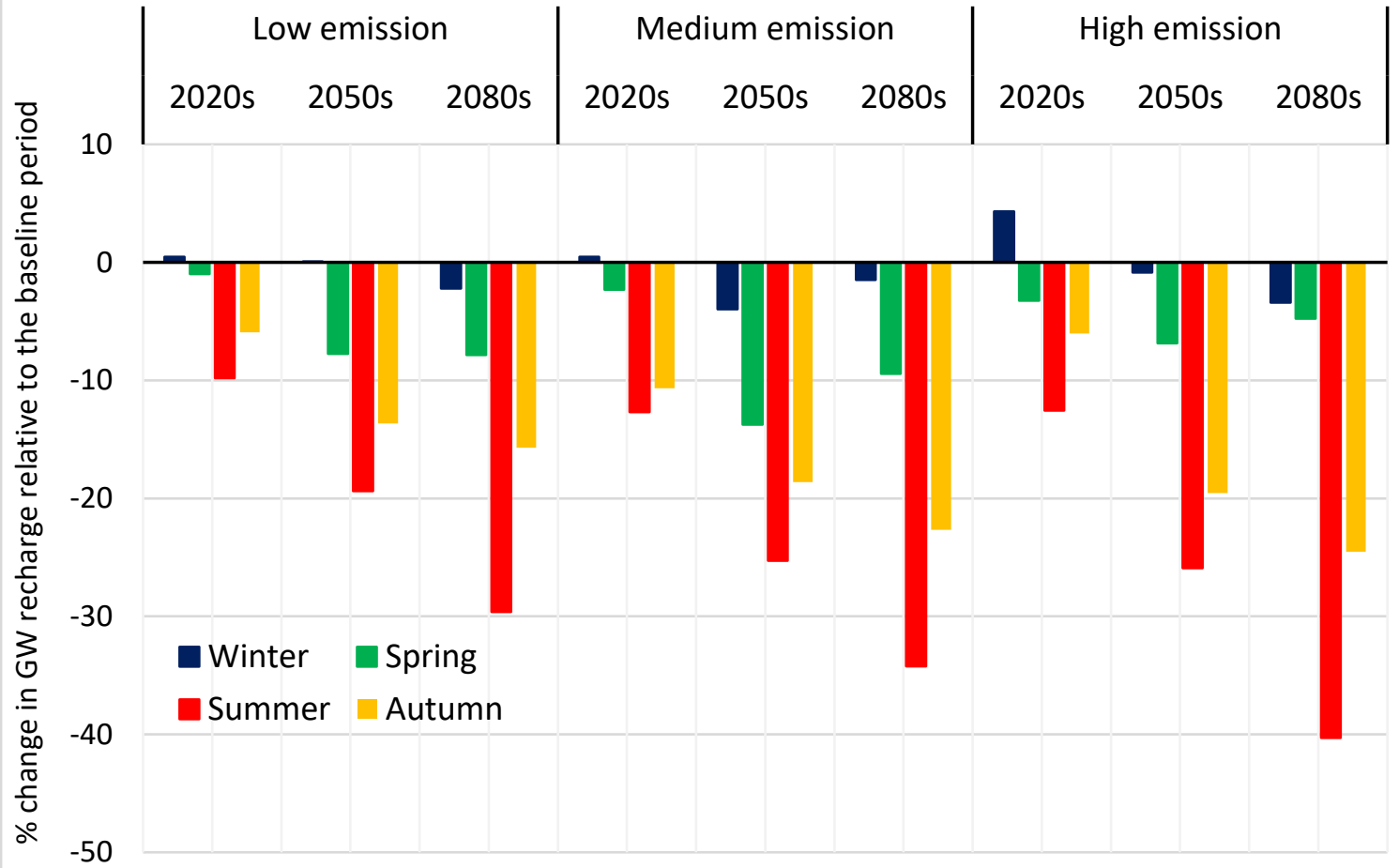

Figure 11: Percentage change in groundwater recharge in the Don Catchment for the different seasons

531 over a selected time period, based on joint probability (a) and Weather Generator (b) of UKCP09 under

532 different climate change scenarios. 
533 In summer months (June, July, August) enhanced evapotranspiration, together with the decreased

534 precipitation, would result in reduced streamflow and groundwater recharge. Higher evapotranspiration

535 combined with lower rainfall during the summer months would result in an increase in soil moisture

536 deficit, which would result in low groundwater recharge during the autumn months under all emission

537 scenarios. However, the severity of the decrease is much higher in the second half of the century under

538 high emission scenarios. Under low emission scenarios the groundwater recharge is likely to decrease

539 by $-2.15 \%$ to $-12 \%$, under medium emission the likely decrease will be within the $-5.93 \%$ to $-14.87 \%$

540 range and under high emission scenarios the projected likely decrease will be within $-3.99 \%$ to $-25.77 \%$

541 range. The higher decrease in groundwater recharge under high emission scenarios would result due to

542 the increase in soil moisture deficit during the summer months. Studies carried out in the Midlands

543 suggest that maintaining water supplies in the 2050s may be challenging due to the limited availability

544 of the water resources (Wade et al., 2013), suggesting that demand-side measures would be required to

545 match the future water supplies availability (Wade et al., 2013).

547 To investigate the impact of climate change, a number of drought indices including soil moisture deficit, wetness index of the root-zone, and reconnaissance drought index were considered. As a result of the drier and warmer climatic conditions, higher water losses by the evapotranspiration, higher soil moisture deficit and low Wetness index were observed (Fig. 12). To illustrate the impact of decreasing rainfall and increasing water losses due to the evapotranspiration, the standardized reconnaissance drought index, $R D I$ was applied. The adjusted RDI was calculated from the net rainfall and actual evapotranspiration of the selected time periods: 2020s, 2050s and 2080s for three emission scenarios

554 (Fig 13). The analysis revealed an increase in number of moderate and severe drought events, more 555 importantly under the medium and high emission scenarios. In comparison to the baseline period, the 556 extreme drought events are likely to double in the later part of the century. Not only the extreme dry events but also, severe drought events are also likely to increase in the future. In addition, the frequency 
559 medium and high emission scenarios.
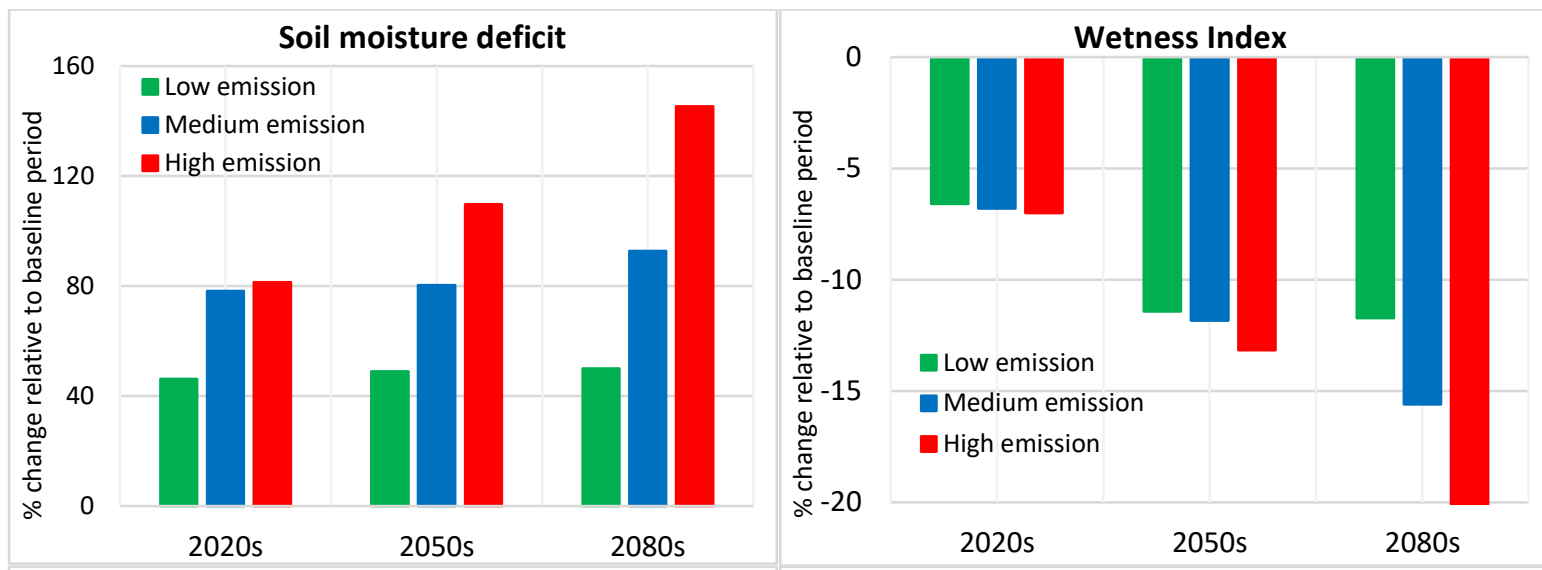

560
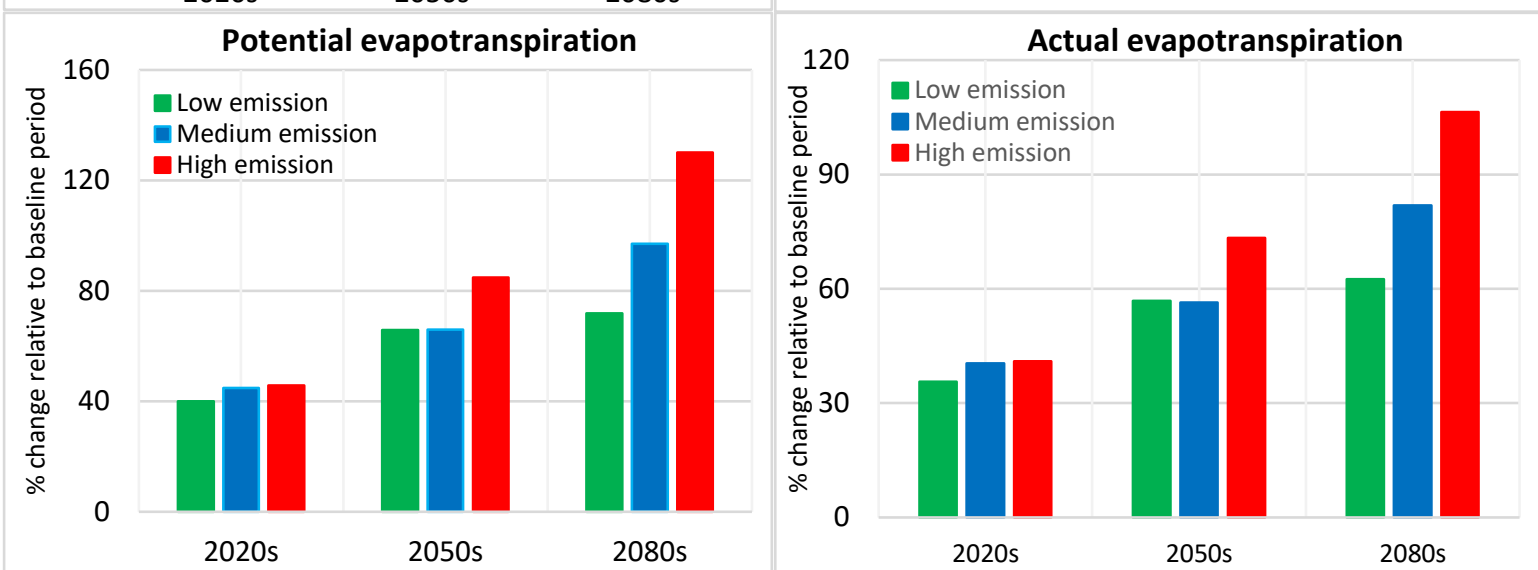

561
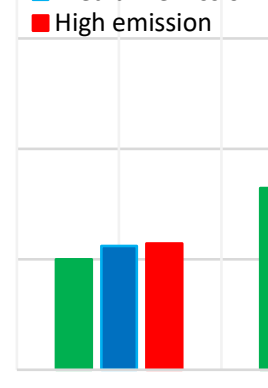

$2020 \mathrm{~s}$

2050s

$2080 \mathrm{~s}$

2050s

2080 s

562 Figure 12: Seasonal changes in soil moisture deficit, actual evapotranspiration and the wetness index

563 of the root zone for the Don Catchment under all emission scenarios base on UKCP09 joint probability. 

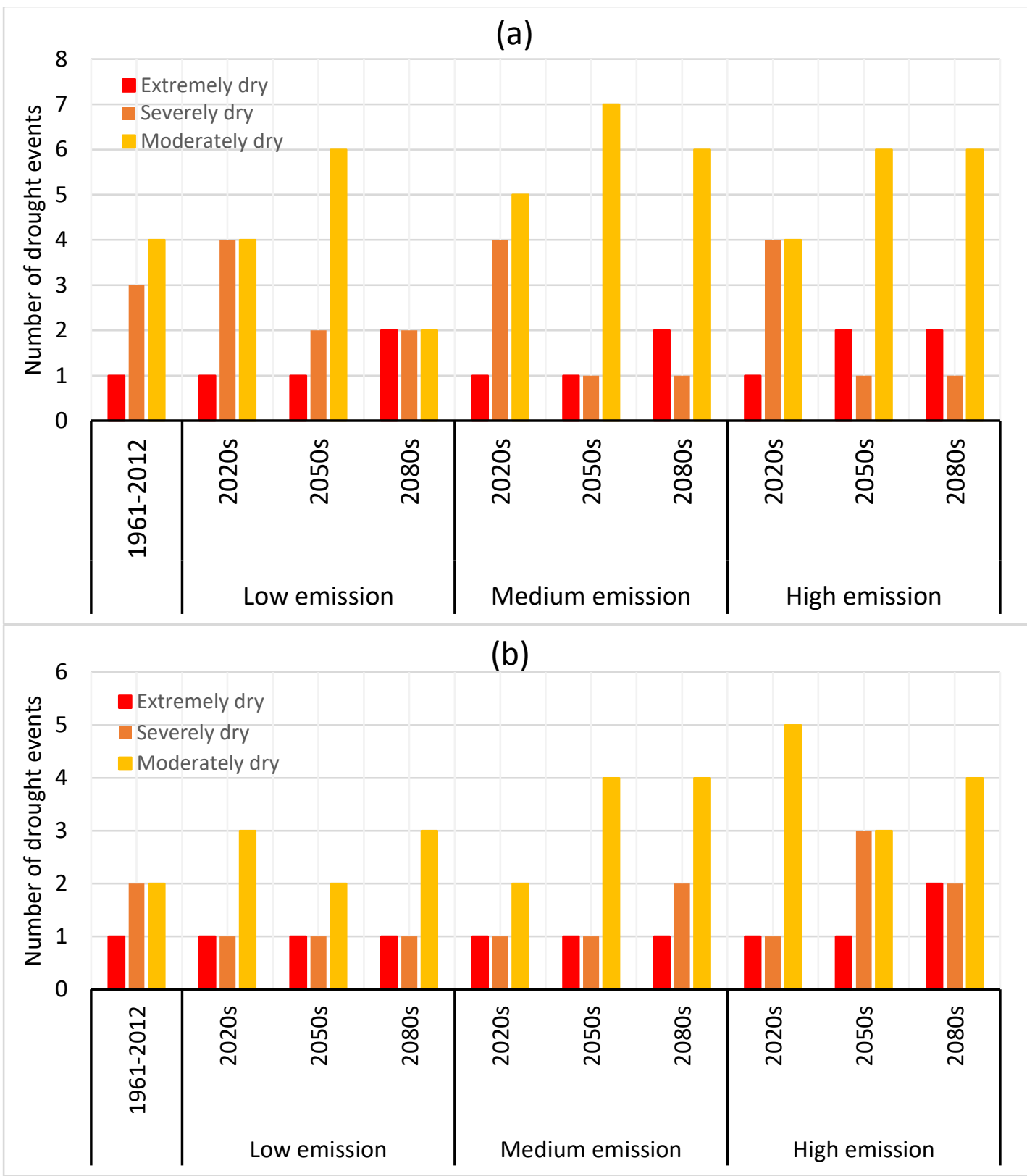

Figure 13: The severity of drought events observed in the Don Catchment under the three emission scenarios for the 2020s, 2050s and 2080s (a) under joint probability and using the weather generator data (b).

\subsection{Impacts of land use changes on the water resources}

571 To study the impact of land use changes on the water balance a number of possible plausible and

572 hypothetical land scenarios were examined (Table 3). The number of tested possible and hypothetical 573 land use changes and the impacts are: 
1. $100 \%$ Grass area replaced by winter barley: Stream flow is likely to increase between $3 \%$ and $6 \%$ while groundwater recharge is likely to increase between 1 and $7 \%$.

2. Grass area replaced by oil seed rape: Stream flow is likely to decrease by up to $3 \%$ in all seasons apart from autumn where it is likely to slightly increase by $<3 \%$, while groundwater is likely to decrease between $\sim 2 \%$ apart from autumn where the recharge is likely to increase by $\sim 2 \%$.

3. $40 \%$ urban expansion replacing grass and arable area: Stream flow is likely to increase by $\sim 1 \%$ and groundwater recharge by $\sim 2 \%$.

4. Replacing $50 \%$ of winter barley by oil seed rape: Stream flow is likely to decrease by $\sim 2 \%$ and groundwater recharge by $\sim 3 \%$

5. Whole catchment as grass area: Stream flow is likely to decrease by $2 \%$ and $8 \%$ and groundwater recharge by $\sim 5 \%$ and $9 \%$.

6. Whole catchment as Broad leaf forest area: The stream flow is likely to decrease between $9 \%$ and $17 \%$ and groundwater recharge between $10 \%$ and $22 \%$.

\section{8}

The expansion of the wooded broadleaf forest would be likely to result in an increase of soil moisture deficit, more specifically during the spring and summer seasons when plants at maximum growth rate and take up much of water and transpiration rates are significant. Urban expansion could result in increased streamflow (likely to increase in flood risk) and increase in groundwater recharge. Increasing conventional crops, like barley replacing grass could result in a slight increase in river flow and a decrease in soil moisture deficit, compared with oilseed rape, which takes up more water during the spring season (Table 3).

Sensitivity analysis to see the combined effect of both climate and land use changes revealed that overall, the effect of the land use changes on the hydrological variables was much less than the effect of climate change. Considering the possible changes in climatic variables and extreme events in the future, sustainable land use practices could potentially be used to mitigate the impact of climate change as the studied catchment is of significance for the water supplies in the Sheffield area 
603 Table 3: Impact of land use changes in the Don Catchment on stream flow and groundwater recharge.

\begin{tabular}{|c|c|c|c|c|c|c|c|}
\hline \multirow{2}{*}{$\begin{array}{l}\text { Hydrological } \\
\text { variables }\end{array}$} & \multicolumn{7}{|c|}{ Land use types } \\
\hline & \multicolumn{2}{|c|}{$\begin{array}{l}100 \% \text { Grass area } \\
\text { replaced by } \\
\text { winter barley }\end{array}$} & $\begin{array}{l}\text { Grass } \\
\text { area } \\
\text { replaced } \\
\text { by oil } \\
\text { seed rape }\end{array}$ & $\begin{array}{l}40 \% \text { urban } \\
\text { expansion } \\
\text { replacing } \\
\text { grass and } \\
\text { arable area }\end{array}$ & $\begin{array}{l}\text { Replacing } \\
50 \% \text { of } \\
\text { winter } \\
\text { barley by } \\
\text { oil seed } \\
\text { rape }\end{array}$ & $\begin{array}{l}\text { Whole } \\
\text { catchment } \\
\text { as grass } \\
\text { area }\end{array}$ & $\begin{array}{l}\text { Whole } \\
\text { catchment } \\
\text { as Broad } \\
\text { leaf forest } \\
\text { area }\end{array}$ \\
\hline \multirow[t]{5}{*}{ River flow } & Season & $\%$ & $\%$ change & $\%$ change & $\%$ change & $\%$ change & $\%$ change \\
\hline & Winter & 6.46 & -2.8 & 1.14 & -1.35 & -2.64 & -12.4 \\
\hline & Spring & 6.10 & -1.2 & 1.13 & -0.50 & -5.22 & -16.6 \\
\hline & Summer & 3.39 & -0.31 & 0.42 & -0.10 & -8.35 & -14.4 \\
\hline & Autumn & 3.57 & 2.4 & -0.05 & -1.14 & -3.90 & -9.01 \\
\hline \multirow{4}{*}{$\begin{array}{l}\text { Groundwater } \\
\text { recharge }\end{array}$} & Winter & 6.53 & -2.01 & 1.40 & -0.47 & -7.80 & -13.48 \\
\hline & Spring & 5.21 & -0.05 & 1.90 & 0.30 & -6.10 & -15.21 \\
\hline & Summer & 0.60 & -1.95 & 1.40 & 0.58 & -9.10 & -21.90 \\
\hline & Autumn & 6.48 & 3.91 & 1.80 & -3.13 & -5.30 & -9.65 \\
\hline
\end{tabular}

604

605

606

607

608

609

610

611

612

613

614

615

616 
The drought indices used in the study were able to identify all the historical drought events. The adjusted reconnaissance drought index calculated using the actual evapotranspiration and the net rainfall, in addition, to the conventional RDI, SPI/SPEI, SMD and WI of the root-zone were used as indicators to identify future drought events. The standardized precipitation index, SPI/SPEI indicated the significantly negative deviation from the average precipitation in the 1970s, specifically in 1975-1976 and 1995-1996. The 1975/1976 drought has been studied in a number of studies including (Perry, 1976, Marsh et al., 2007). During the 1995/1996 drought period, water resources in the Northern England and in the Midlands remained fragile as April to November 1995 rainfall was the second lowest in the 228 years for England and Wales (Marsh and Turton, 1996). All the applied drought indices including reconnaissance drought index $(R D I)$, soil moisture deficit, $S M D$ and the Wetness index, WI of the rootzone (Figures 7-9) identified these drought events. During these drought events, the RDI, SPI/SPEI were well below -2 , which identifies them as 'extreme drought' events (caused by extremely low rainfall and high evapotranspiration). Under current land use practices, a further increase in likelihood of extreme drought events, specifically under medium and high emission scenarios in the middle and the latter part of the century (Figure 13) due to an increase in temperature, resulting in higher water losses by evapotranspiration, a decrease in rainfall, an increase in soil moisture deficit consequently would result in more frequent and severe drought in the future. This would further increase the pressure on water resources due to changes in land use practices.

The land use type would significantly change in the future, especially due to urbanisation, as urbanisation would further increase pressure on water resources in the Don catchment. The other key land use changes are the agricultural land use practices, which are driven by the farmers' decisions which are market based, as well as the availability of investment, subsidies and the socio-cultural attributes of individual farmers. Increasing woodland area would significantly reduce both stream flow and groundwater recharge. 
642 The application of a wider range of drought indices could be used to identify different types of droughts.

643 For example, in agriculture, when soil moisture deficit, SMD or Wetness Index, WI of the root zone,

644 reach a critical level, crops will require irrigation, particularly during the summer months. This will

645 require reliable water supplies to secure adequate yield. The $W I$ value, if close to 1 , would indicate a

646 wet catchment with a possible runoff generation during the next rainfall event, therefore, it is a help to

647 reservoir managers to know the $W I$ in real time. $R D I$ would be helpful for short and long-term planning

648 by water authorities and water companies. Therefore, the findings from the modelling work could be

649 used to review the future surface water abstraction regulations to be in line with the water resources

650 availability as predicted by the hydrological models and in possible planning of building new water

651 infrastructure to increase the water storage in relation to increasing future water demand.

652 The DiCaSM model proved to be a good tool to predict river flow and recharge to groundwater and can

653 simulate the effects of climate change on the different elements of the hydrological cycle. The future

654 climate change scenarios suggested a significant decrease in groundwater recharge although climate

655 models project an increase in winter rainfall but such increase could be counter balanced by an increase

656 in evapotranspiration and increase of soil moisture deficit during the summer and autumn seasons. The

657 streamflow decrease would affect the Don catchment more as there are 23 reservoirs within the

658 catchment, which are recharged during the winter season. Considering the possible decrease in

659 groundwater recharge and streamflow and the increasing possibility of droughts in the future. New

660 investment will be required if water demand is not met through greater water use efficiency or by

661 alternative sources to traditional reservoirs, such as rainwater harvesting systems (Zhang and Hu, 2014)

662 or by reducing evaporation from the reservoirs by for example, floating solar panels, spreading

663 ecologically friendly agents on water surface or an ultra-thin layer of organic molecules on their surface

664 (Alamaro et al., 2012). The implication of surface water abstractions during drought and low flow

665 periods would reduce river flows possibly below the minimum environmental flow. Alternatively,

666 restrictions on abstraction to maintain the minimum environmental flows may restrict crop yields and

667 food production. 
The model calibration and validation results showed a good agreement between the observed the simulated flow and overall model efficiency using the NS index was above $82 \%$ for the 52 years' study period. In addition to the stream flow, the DiCaSM hydrological model identified all drought events using the drought indices: RDI, SMD, and the WI in the 1970s but also during the 1980s, 1990s and the most recent ones in 2010-2012. The analysis revealed that the standard RDI, based on gross rainfall and potential evapotranspiration, showed slightly higher severity than the adjusted $R D I$. The latter is based on realistic input of net rainfall (excluding interception losses by vegetation cover) and actual evapotranspiration, which reflects the actual losses from soil and plants. Under the UKCP09 climate change projection, the streamflow and the groundwater recharge significantly decreased, more specifically during the summer months, while the severity of the drought events significantly increased over time. All the applied drought indices $(S M D, W I$, and $R D I)$ identified an increase in the severity of the drought under future climatic change scenarios. Under high emission scenarios, the severity was higher as this severity was associated with the increasing temperature and subsequently increasing water losses by evapotranspiration, thus reducing soil moisture availability, surface runoff to streams and recharge to groundwater. These findings would help in planning for perhaps extra water infrastructure work if needed, such as building more reservoirs or water transfer pipelines from water-rich to waterpoor regions and planning for irrigation water demand under different climatic conditions. The study catchment is of significance as there are twenty-three reservoirs in the catchment boundary, which significantly contribute into the water supply of the catchment. The findings of this study can also be useful in revising the "Catchment Abstraction Management Strategies, CAMS" for the Don catchment.

\section{Acknowledgement}

The authors acknowledge the NERC funding for this 4-years "Drought Risk and You, DRY" project, grant reference NE/L010292/1. We are also very thankful to our CEH colleagues especially Yan Weigang, Egon Dumont, Virginie Keller and James Blake who helped us in preparing the soil model input data. The authors are also very thankful to Lindsey McEwen who helped in organising Local 
Advisory Group meetings for the Don catchment. The authors would like to acknowledge the data

sources: Background mapping from Ordnance Survey ('1:250 000 Scale Colour Raster'). Catchment boundary and gauging station location data from Centre for Ecology and Hydrology (Morris et al., 1990, Morris and Flavin, 1994). River and waterbody data from Centre for Ecology and Hydrology ('Digital Rivers 50km GB' Web Map Service). Land cover data from Centre for Ecology and Hydrology (Land Cover Map 2007 (25m raster, GB) Web Map Service (Morton et al., 2011). Standardized Precipitation Index time series for IHU groups (1961-2012) [SPI_IHU_groups] data licensed from NERC Centre for Ecology \& Hydrology. Soils data courtesy of Cranfield University (1:250 000 Soilscapes for England and Wales Web Map Service). Hydrogeology data from British Geological Survey (DiGMapGB 1:625 000 scale digital hydrogeological data).

\section{References:}

AFZAL, M., GAGNON, A. S. \& MANSELL, M. G. 2015. The impact of projected changes in climate variability on the reliability of surface water supply in Scotland. Water Science and Technology: Water Supply, 15, 736-745.

ALAMARO, M., EMANUEL, K. \& LANGER, R. S. 2012. Surface film distribution system and method thereof. Google Patents.

ALEXANDER, L. V., TETT, S. F. \& JONSSON, T. 2005. Recent observed changes in severe storms over the United Kingdom and Iceland. Geophysical Research Letters, 32.

ALLEN, R. G., PEREIRA, L. S., RAES, D. \& SMITH, M. 1998. Crop evapotranspiration-Guidelines for computing crop water requirements-FAO Irrigation and drainage paper 56. Fao, Rome, 300, D05109.

BACHMAIR, S., TANGUY, M., HANNAFORD, J. \& STAHL, K. 2018. How well do meteorological indicators represent agricultural and forest drought across Europe? Environmental Research Letters, 13, 034042.

BENTO, V. A., GOUVEIA, C. M., DACAMARA, C. C. \& TRIGO, I. F. 2018. A climatological assessment of drought impact on vegetation health index. Agricultural and Forest Meteorology, 259, 286-295.

BURKE, E. J., PERRY, R. H. \& BROWN, S. J. 2010. An extreme value analysis of UK drought and projections of change in the future. Journal of Hydrology, 388, 131-143.

CEH. 2014. CEH digital river network of Great Britain web map service [Online]. Available: https://data.gov.uk/dataset/3c7ea82e-83e0-45a3-9a3f-8ba653b3211b/ceh-digital-rivernetwork-of-great-britain-web-map-service [Accessed 2014].

CROPPER, T. E. \& CROPPER, P. E. 2016. A 133-year record of climate change and variability from Sheffield, England. Climate, 4, 46.

DE CÁCERES, M., MARTIN-STPAUL, N., TURCO, M., CABON, A. \& GRANDA, V. 2018. Estimating daily meteorological data and downscaling climate models over landscapes. Environmental Modelling \& Software, 108, 186-196.

FORESTIERI, A., ARNONE, E., BLENKINSOP, S., CANDELA, A., FOWLER, H. \& NOTO, L. V. 2018. The impact of climate change on extreme precipitation in Sicily, Italy. Hydrological Processes, 32, 332-348.

FOWLER, H. \& KILSBY, C. 2002. A weather-type approach to analysing water resource drought in the Yorkshire region from 1881 to 1998. Journal of Hydrology, 262, 177-192. 
GUDMUNDSSON, L., BREMNES, J., HAUGEN, J. \& ENGEN-SKAUGEN, T. 2012. Downscaling RCM precipitation to the station scale using statistical transformations-a comparison of methods. Hydrology and Earth System Sciences, 16, 3383.

GUPTA, H. V., KLING, H., YILMAZ, K. K. \& MARTINEZ, G. F. 2009. Decomposition of the mean squared error and NSE performance criteria: Implications for improving hydrological modelling. Journal of Hydrology, 377, 80-91.

HAKALA, K., ADDOR, N. \& SEIBERT, J. 2018. Hydrological Modeling to Evaluate Climate Model Simulations and Their Bias Correction. Journal of Hydrometeorology, 19, 1321-1337.

HOUGH, M., PALMER, S., WEIR, A., LEE, M. \& BARRIE, I. 1997. The Meteorological Office rainfall and evaporation calculation system: MORECS version 2.0 (1995). An update to hydrological memorandum, 45, 80.

JACKSON, C. R., BLOOMFIELD, J. P. \& MACKAY, J. D. 2015. Evidence for changes in historic and future groundwater levels in the UK. Progress in Physical Geography, 39, 49-67.

KALMA, J., BATES, B. \& WOODS, R. 1995. Predicting catchment-scale soil moisture status with limited field measurements. Hydrological processes, 9, 445-467.

KRAUSE, P., BOYLE, D. \& BÄSE, F. 2005. Comparison of different efficiency criteria for hydrological model assessment. Advances in geosciences, 5, 89-97.

KUNZ, J., LÖFFLER, G. \& BAUHUS, J. 2018. Minor European broadleaved tree species are more drought-tolerant than Fagus sylvatica but not more tolerant than Quercus petraea. Forest Ecology and Management, 414, 15-27.

MARSH, T., COLE, G. \& WILBY, R. 2007. Major droughts in England and Wales, 1800-2006. Weather, 62, 87-93.

MARSH, T. \& GREEN, S. 1997. UK hydrological review 1997. 2nd ed.: Centre for Ecology and Hydrology.

MARSH, T. \& TURTON, P. 1996. The 1995 drought—a water resources perspective. Weather, 51, 4653.

MCKEE, T. B., DOESKEN, N. J. \& KLEIST, J. The relationship of drought frequency and duration to time scales. Proceedings of the 8th Conference on Applied Climatology, 1993. American Meteorological Society Boston, MA, 179-183.

MORRIS, D. \& FLAVIN, R. 1994. Sub-set of the UK $50 \mathrm{~m}$ by $50 \mathrm{~m}$ hydrological digital terrain model grids. NERC, Institute of Hydrology, Wallingford.

MORRIS, D., FLAVIN, R. \& MOORE, R. 1990. A digital terrain model for hydrology.

MORTON, D., ROWLAND, C., WOOD, C., MEEK, L., MARSTON, C., SMITH, G., WADSWORTH, R. \& SIMPSON, I. 2011. Final Report for LCM2007-the new UK land cover map. Countryside Survey Technical Report No 11/07.

NASH, J. E. \& SUTCLIFFE, J. V. 1970. River flow forecasting through conceptual models part I-A discussion of principles. Journal of hydrology, 10, 282-290.

NRFA. 2014. National River flow Archive [Online]. Available: http://nrfa.ceh.ac.uk/ [Accessed 2014].

PARRY, S., WILBY, R. L., PRUDHOMME, C. \& WOOD, P. J. 2016. A systematic assessment of drought termination in the United Kingdom.

PERRY, A. 1976. The long drought of 1975-76. Weather, 31, 328-336.

RAGAB, R. \& BROMLEY, J. 2010. IHMS - Integrated Hydrological Modelling System. Part 1. Hydrological processes and general structure. Hydrological processes, 24, 2663-2680.

RAGAB, R., BROMLEY, J., DÖRFLINGER, G. \& KATSIKIDES, S. 2010. IHMS-Integrated Hydrological Modelling System. Part 2. Application of linked unsaturated, DiCaSM and saturated zone, MODFLOW models on Kouris and Akrotiri catchments in Cyprus. Hydrological processes, 24, 2681-2692.

ROBINSON, E., BLYTH, E., CLARK, D., COMYN-PLATT, E., FINCH, J. \& RUDD, A. 2015. Climate hydrology and ecology research support system potential evapotranspiration dataset for Great Britain (1961-2015)[CHESS-PE].

ROUNSEVELL, M. \& REAY, D. 2009. Land use and climate change in the UK. Land Use Policy, 26, S160-S169.

SENEVIRATNE, S. I. 2012. Climate science: Historical drought trends revisited. Nature, 491, 338. 
SHIFERAW, B. A., OKELLO, J. \& REDDY, R. V. 2009. Adoption and adaptation of natural resource management innovations in smallholder agriculture: reflections on key lessons and best practices. Environment, development and sustainability, 11, 601-619.

SOLANDER, K. C. \& WILSON, C. J. 2018. The Cape Town drought: what is happening and will it happen again? : Los Alamos National Lab.(LANL), Los Alamos, NM (United States).

SPRAGGS, G., PEAVER, L., JONES, P. \& EDE, P. 2015. Re-construction of historic drought in the Anglian Region (UK) over the period 1798-2010 and the implications for water resources and drought management. Journal of hydrology, 526, 231-252.

TANGUY, M., DIXON, H., PROSDOCIMI, I., MORRIS, D. \& KELLER, V. 2016. Gridded estimates of daily and monthly areal rainfall for the United Kingdom (1890-2015)[CEH-GEAR]. NERC Environmental Information Data Centre, doi, 10.

THE_DON_NETWORK. 2018. Our plan for the River Don [Online]. Available: https://dcrt.org.uk/wpcontent/uploads/2013/05/6541-1+Don+Network+Report+lo+res.pdf [Accessed 24/10/2018 2018].

THORNTHWAITE, C. W. 1948. An approach toward a rational classification of climate. Geographical review, 38, 55-94.

TIRIVAROMBO, S., OSUPILE, D. \& ELIASSON, P. 2018. Drought monitoring and analysis: Standardised Precipitation Evapotranspiration Index (SPEI) and Standardised Precipitation Index (SPI). Physics and Chemistry of the Earth, Parts $A / B / C$.

TSAKIRIS, G., PANGALOU, D. \& VANGELIS, H. 2007. Regional drought assessment based on the Reconnaissance Drought Index (RDI). Water resources management, 21, 821-833.

VANGELIS, H., TIGKAS, D. \& TSAKIRIS, G. 2013. The effect of PET method on Reconnaissance Drought Index (RDI) calculation. Journal of Arid Environments, 88, 130-140.

VICENTE-SERRANO, S. M., BEGUERÍA, S. \& LÓPEZ-MORENO, J. I. 2010. A multiscalar drought index sensitive to global warming: the standardized precipitation evapotranspiration index. Journal of climate, 23, 1696-1718.

WADE, S. D., RANCE, J. \& REYNARD, N. 2013. The UK climate change risk assessment 2012: assessing the impacts on water resources to inform policy makers. Water Resources Management, 27, 1085-1109.

WANG, H., TETZLAFF, D. \& SOULSBY, C. 2018. Modelling the effects of land cover and climate change on soil water partitioning in a boreal headwater catchment. Journal of Hydrology, 558, 520-531.

WANG, L. \& CHEN, W. 2014. A CMIP5 multimodel projection of future temperature, precipitation, and climatological drought in China. International Journal of Climatology, 34, 2059-2078.

WILBY, R. L., PRUDHOMME, C., PARRY, S. \& MUCHAN, K. 2015. Persistence of hydrometeorological droughts in the United Kingdom: A regional analysis of multi-season rainfall and river flow anomalies. Journal of Extreme Events, 2, 1550006.

ZARCH, M. A. A., SIVAKUMAR, B. \& SHARMA, A. 2015. Droughts in a warming climate: A global assessment of Standardized precipitation index (SPI) and Reconnaissance drought index (RDI). Journal of Hydrology, 526, 183-195.

ZHANG, X. \& HU, M. 2014. Effectiveness of rainwater harvesting in runoff volume reduction in a planned industrial park, China. Water resources management, 28, 671-682. 